\title{
Tendiendo puentes para fortalecer la articulación entre la planificación institucional y la planificación de aula*
}

Mariela Solari **

\section{Resumen}

El presente trabajo de investigación se desarrolló con relación a las dificultades para articular la planificación institucional en Educación Primaria con la planificación de aula. Este problema se identificó en un centro escolar confesional habilitado por el Consejo de Educación Primaria e Inicial, ubicado en la zona oeste de Montevideo.

La investigación responde a una metodología de corte cualitativo a través del "Estudio de casos" que nos permitió focalizar la situación, describirla, comprenderla y examinarla en función de un contexto determinado.

Para el diagnóstico, las técnicas utilizadas fueron: entrevistas exploratorias y en profundidad (a directivos y docentes), análisis de documentos y cuestionario autoadministrado (a todos los docentes). Se incorporaron diferentes dispositivos de análisis organizacional (matriz, iceberg, FODA), lo que nos habilitó a documentar, sistematizar y evaluar la experiencia.

El estudio diagnóstico realizado identifica a la dimensión organizacional como la más comprometida asociada a los siguientes factores: ausencia de espacio de coordinación; escasez de estrategias para el abordaje de problemas organizacionales; falta de intercambio de prácticas exitosas; inexistencia de acuerdos metodológicos básicos y dificultades para el trabajo en equipo.

Basándose en el problema encontrado en el diagnóstico, se diseñó un Proyecto de Mejora Organizacional (PMO) cuyo objetivo general fue fortalecer y tender puentes entre el objetivo y misión del colegio expresados en el ideario, el objetivo principal Proyecto Educativo de Centro (PEC); el Proyecto Curricular de Centro (PCC) y la Planificación de Aula (PA) realizada por los docentes con el fin de mejorar los aprendizajes de los niños y niñas.

PALABRAS CLAVE: Planificación Educativa- Cultura Organizacional- Desarrollo Organizacional- Planeamiento Estratégico Situacional.

\begin{abstract}
The present paper intents to find answers to the problem of poor connection between Primary School institutional planning, and classroom work and planning. The conflict was identified in a Primary school of Montevideo west zone. The present research uses qualitative methodology materialized in Case Study, a method that helped to focus on a problem, describe, comprehend, and examine it in a particular social context. In order to make a good diagnose different techniques were used as well as in depth and exploratory interviews (made to headmasters and professors), document analysis, self-administered questionnaire (applied to professors). Many organisational tools (matrix, iceberg, FODA) allowed us to document, systematize and evaluate the experience. Diagnose identifies organisational dimension as the most committed due to the existence of different factors such us: abscence of coordination
\end{abstract}


space, strategies to solve organizational problems, lack of exchanging of good practices, absence of planning and hard difficulties to develop team work. Looking for solutions, an Organisational Improving Project was designed, for which the main objective was to fortify the connection between theory and planning of the School, with the particular aim of Primary Centre, the Curricular Project, and the Classroom Planning made by professors with the main goal of improving child learning process.

KEY WORDS: Educational Planning- Organizational Culture- Organizational DevelopmentSituational Strategic Planning 


\section{Referentes conceptuales}

Como muestra el esquema que se presenta a continuación, en el marco teórico hemos trazado un recorrido por los referentes conceptuales en función de los cuales analizamos el tema central del estudio en relación a la planificación educativa en el centro escolar: la articulación entre la planificación institucional y la planificación de aula.

En la complejidad de la relación entre sociedad y educación, ponemos la mirada en el fortalecimiento de las estructuras sociales que promueven la equidad y cohesión social, para obtener mejores resultados educativos.

Estos resultados dependerán en buena medida del tipo de cultura organizacional que caracterice al centro educativo. Desentrañar el tipo de cultura, identificarla y reconocerla permitirá generar condiciones para que la escuela progrese y se proyecte.

La cultura organizacional está íntimamente relacionada con las posibilidades que la escuela tiene de producir y generar conocimiento, y en consecuencia con el estadio de desarrollo organizacional en el que se encuentra.

Consideramos el método y la prospectiva como conceptos tributarios al de planificación institucional. El Planeamiento Estratégico Situacional (PES) corresponde al modelo de planificación institucional en el cual nos hemos posicionado por favorecer los procesos de desarrollo organizacional orientados a la producción y gestión del conocimiento organizacional.

Figura 1. Recorrido por el marco teórico

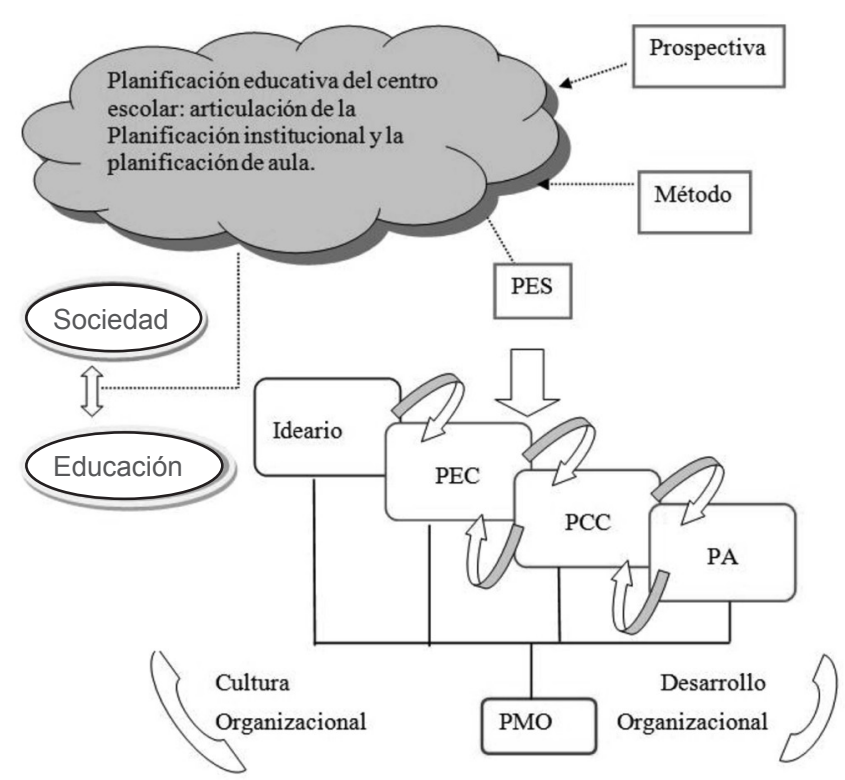

Desde esta perspectiva habrá de darse la articulación entre los instrumentos de planificación que corresponden al ideario, al proyecto educativo de centro (PEC), al Proyecto Curricular de Centro (PCC), a la Planificación de Aula (PA) y los Proyectos de Mejora Organizacional (PMO) que oportunamente se van diseñando para conducir la escuela hacia la mejora. 


\section{1.a. El contrato entre Sociedad y Educación: revisar la mirada}

Uno de los fines de toda organización educativa consiste en la transmisión de la herencia cultural que se realiza a través de la distribución de los saberes por medio del desarrollo curricular, formando así a las nuevas generaciones con el objeto de ofrecer herramientas que permitan su inclusión social y la futura inserción en el mundo del trabajo.

En América latina las reformas educativas de la década de los años '90 apuntaron -entre otros aspectos- a la expansión cuantitativa de la escolarización a la vez que se fue instalando una preocupación por la calidad de la enseñanza y los logros del aprendizaje de los alumnos (Tedesco, 2005). En nuestro país no solo ha aumentando la matrícula en Educación Inicial, Primaria, Básica y Superior, sino que en el último quinquenio los recursos económicos destinados a la educación a través de Producto Bruto Interno (PBI) corresponden al 4.5\%. Sin embargo estas mejoras no se reflejan en los resultados de aprendizaje obtenidos por los alumnos (Cardozo, 2008).

La explicación a estas dificultades encuentran su origen tanto en la resistencia a los cambios, ya sea a los que afectan las estructuras (cambios de tipo 1), como a los que se producen dentro de las mismas; (cambios tipo 2) (Watzlawick, 1985); como en las políticas educativas que se renuevan cada cinco años; en el corporativismo de algunos actores; en la rotación docente debido al mecanismo de elección de cargos y en la universalización de la matrícula con las consecuencias que ésta conlleva, entre otros aspectos, al no ir acompañada de una cobertura en calidad que asegure la igualdad de oportunidades para todos.

Pero también hemos incorporado a la explicación, el análisis que realiza Tedesco (2011), sobre las dos características más importantes de la sociedad moderna en relación a la creciente importancia del aprender a aprender: la velocidad con la que se producen nuevos conocimientos y la posibilidad de acceder a una gran cantidad de datos e información que es necesario aprender a jerarquizar y seleccionar, para poder utilizarla. La educación ya no podrá estar dirigida a la mera transmisión de información y conocimientos sino a desarrollar la capacidad de producirlos y utilizarlos. Quienes no desarrollen estas capacidades pueden quedar confinados en los sectores sociales menos favorecidos.

Numerosos estudios y evaluaciones como los resultados de las pruebas PISA 2009 (ANEP/ CODICEN /DIEE. Programa PISA, 2010) muestran la relación que existe entre la desigualdad social claramente asociada a las condiciones socioeconómicas de las familias y la brecha de desempeño en los logros de aprendizaje de los alumnos. Uno de los dilemas del sistema educativo público es cómo evitar que los condicionamientos socioeconómico - familiares sean determinantes de la desigualdad educativa que se genera como una consecuencia del origen sociocultural de los alumnos.

En este contexto, Tedesco (2005) señala que las relaciones tradicionales entre educación y equidad social deben ser revisadas. Se vuelve necesario desplazar la mirada desde un hacer hincapié en la educación para lograr la equidad social, a generar un mínimo básico de equidad y cohesión social como condición necesaria para que se realice un proceso educativo exitoso.

Es en este sentido, en nuestro país se han tomado decisiones políticas orientadas a fortalecer la intervención a edades tempranas (educación inicial obligatoria a los 3, 4 y 5 años, creación de Centros de Atención a la Infancia y a la Familia (CAIF), escuelas de tiempo completo, distribución de textos escolares, incorporación al Fondo Nacional de Salud (FONASA) a los hijos de desocupados, asignaciones familiares) ya que es fundamental intervenir en el momento preciso en que se produce la formación básica del capital cognitivo de las personas (Cardozo, 2008). 
Este análisis de la realidad social adopta especial significación en la escuela donde se realizó el estudio, porque aunque se trató de un centro privado, posee un alumnado con características peculiares por el contexto del que proceden.

Tomamos como referencia la categorización de contexto sociocultural de los centros educativos de Educación Primaria, construida combinando información relativa al nivel educativo de las madres de los alumnos y el equipamiento del hogar. De la misma resultan cuatro categorías de contexto: muy desfavorable, desfavorable, medio y favorable (ANEP/ Observatorio de la Educación, 2009). En la escuela, en lo que refiere al contexto sociocultural, varía entre favorable y desfavorable, razón por la cual la escuela cuenta con un sistema de becas para aquellas familias que no pueden acceder a la cuota y un merendero para apoyar a los más necesitados (Proyecto Educativo de Centro, 2006).

Tedesco (2005), agrega, que en la agenda educativa actual debemos incluir la dimensión pedagógica y aquí resulta fundamental el rol de los docentes, o sea, quién y cómo enseña.

Figura 2. Relaciones entre Equidad y Proceso educativo exitoso

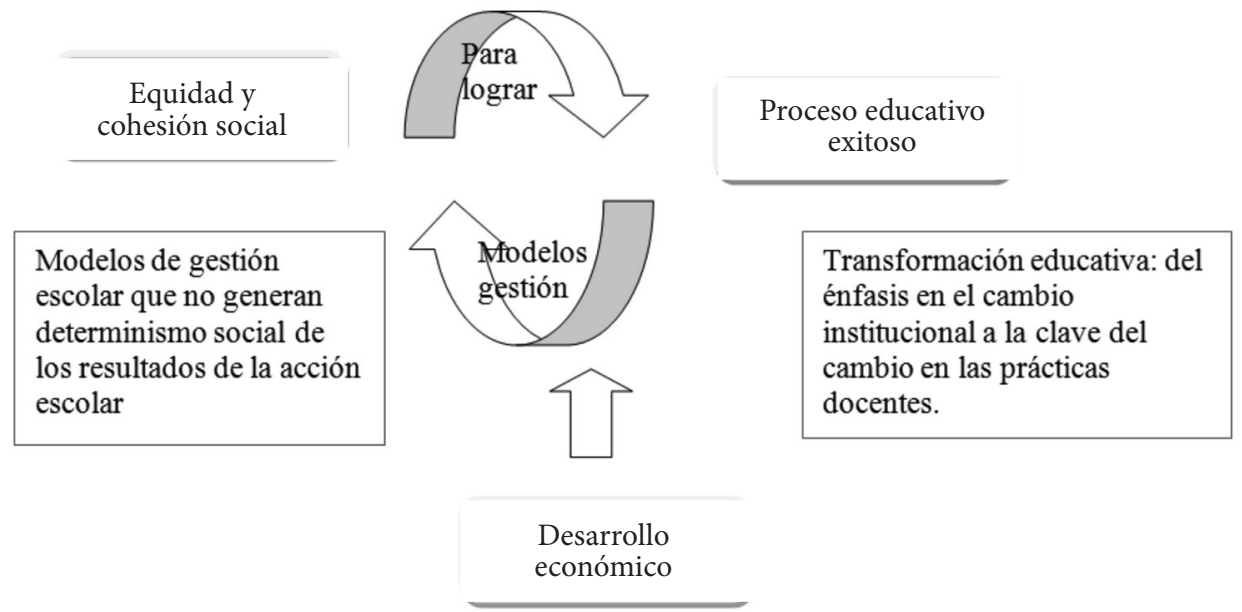

Fuente: elaboración basada en aportes de Tedesco (2005).

Según el autor, si bien las reformas de los años 90 ponían el acento en el cambio institucional (cambios en los contenidos curriculares y proyectos de centro) para lograr mejores aprendizajes, la experiencia demostró que este movimiento no provocó los cambios esperados en los procesos de enseñanza y de aprendizaje que tienen lugar en el aula y en la escuela.

Hoy adquieren mayor relevancia las hipótesis que establecen que para que las reformas lleguen al aula y se modifiquen los aprendizajes, la variable clave es el docente, con sus saberes, sus métodos y sus representaciones.

Aunque también sabemos que las prácticas docentes no cambian exclusivamente porque cambien los programas o los planes, para que las prácticas de enseñanza y aprendizaje mejoren y consecuentemente lo hagan los resultados educativos, se necesita de profesionales de la educación que se informen, adquieran nuevos conocimientos, sean capaces de cambiar los modelos mentales profundamente arraigados (Senge, 1992) y además, contextualizar las nuevas propuestas y saberes en una práctica sobre la cual reflexionen permanentemente de forma individual y colectiva. 
Resulta fundamental restablecer y recomponer la confianza en dos sentidos: con relación a la instituciones educativas y con relación a una pedagogía basada en la confianza de los educadores con respecto a las capacidades de aprendizaje de sus alumnos (evitando el efecto Pigmalión o profecía autocumplida: cuando las personas tienen de antemano a una situación, ciertas expectativas en función de las cuales actúan de modo tal que finalmente se vuelven ciertas).

Estos procesos se verán favorecidos u obstaculizados por el tipo de cultura organizacional que caracterice al centro educativo, por ello resulta importante identificarla, reconocerla y generar condiciones para que la escuela progrese y se proyecte con relación a la situación en la que se encuentre.

\section{1.b. Desentrañando la cultura organizacional de la escuela}

Cada centro educativo posee una determinada cultura organizacional que lo hace particular en sus posibilidades y potencialidades internas para emprender un proceso de mejora. Comprender las características del centro resulta clave para efectivizar el acercamiento al mismo cuando se trata de asesorar, favoreciendo procesos de aprendizaje y desarrollo organizacional.

La cultura organizacional de un centro educativo es un aspecto fundamental a la hora de conseguir los objetivos que la escuela se fije. Toda organización posee un fuerte componente social e histórico con normas, rutinas, hábitos, roles, patrones de conducta y de análisis de la realidad que le son propios y constituyen un estilo que es la mejor respuesta de funcionamiento que se ha podido dar.

Dentro de la dinámica institucional conviven lo instituido es decir lo fijo y estable con lo instituyente: lo cuestionado, criticado, lo que refiere a la propuesta opuesta o de transformación.

Barriga (1979: 25) citando a Lapassade plantea que "La institución sólo puede definirse por la dialéctica social permanente entre las fuerzas instituyentes y las fuerzas instituidas". El autor manifiesta que la institución no puede explicarse solo por lo instituido, sino que se halla entre lo instituido y lo instituyente, entre lo que está normatizado y lo que emerge creativamente de las personas. La adaptación al cambio de una institución deviene de la relación entre lo instituyente y lo instituido, lo que explica la institucionalización de los mismos.

La actitud pasiva frente a lo instituido y la actitud activa hacia lo instituyente, caracterizan la cultura de una organización.

Como plantea De La Torre (1998), en cada centro educativo se pueden visualizar ciertas cuestiones que reflejan su "estado de salud" y que nos permiten conocer cómo es la cultura organizacional del mismo. Estos aspectos refieren al estilo de liderazgo y gestión; al grado de confianza, motivación y compromiso de los integrantes de la comunidad educativa; a la percepción positiva o negativa que los miembros tienen con relación al centro; a las formas de participación; a las posibilidades de realizar trabajo en equipo; al tipo de relaciones interpersonales; al manejo de los conflictos y a las políticas de personal.

Para definir e identificar el tipo de cultura organizacional que la escuela posee, recurrimos a las tipologías propuestas por Hargreaves (1996), Hopkins (1996), Frigerio (1999) y Fernández (2001). Así, caracterizamos la cultura organizacional de la escuela donde se realizó la investigación como individualista, balcanizada, descaminada, regresiva, percibida como cuestión de familia y estancada o de aprendizaje empobrecido. 
Pero la cultura organizacional no es fija, ni rígida, ni inmutable, de manera que es posible acompañar procesos de desarrollo hacia escenarios más productivos para toda la comunidad escolar, apuntando a un centro donde predomine un estilo colaborativo, dinámico, progresista y donde la gestión sea una cuestión de consenso. A esta situación se refieren Fullan y Hargreaves (1996), cuando nos proponen pasar "de escuelas estancadas o de aprendizaje empobrecido a escuelas en movimiento".

\section{1.c. Reconocer y promover el desarrollo organizacional}

La cultura de un centro educativo está íntimamente relacionada con las posibilidades que la escuela tiene de producir y generar conocimiento y en consecuencia con el estadio de desarrollo organizacional en el que se encuentra.

Gairín (2004), nos propone una tipología de las organizaciones que refiere a los diferentes "estadios" evolutivos. Conocerlos permite determinar el escenario en el que un centro educativo se halla, a los efectos de poder proponer planes de mejora que le permitan al mismo, evolucionar gradualmente hacia un estadio superior.

"La situación de las organizaciones suele ser diferente aunque nos movamos en un mismo contexto socio-cultural. La especial manera como se relacionan sus componentes, la acción diferenciada de la dirección, la forma en que se aplica el proceso organizativo, la propia historia institucional y sus inquietudes en relación con la mejora, configuran diferencias y dan una personalidad única y particular a cada institución y a cada proceso organizativo" (Gairín, 2004:18).

Siguiendo al mismo autor, presentamos la sucesión de estadios organizacionales y los diferentes aspectos que caracterizan a cada uno de ellos.

Primer estadio: la organización como marco. El centro educativo funciona como un espacio donde se recibe y aplica pasivamente un cierto programa. La organización actúa como soporte que podrá facilitar o no el desarrollo de dicho programa, proporcionando espacios, tiempos, normativa, recursos humanos y otros requerimientos, adecuando los recursos a las tareas asignadas.

Segundo estadio: la organización como contexto. En este segundo estadio, más evolucionado que el anterior, la organización tiene una posición más activa ya que existen explicitados planteamientos institucionales y como ser el Proyecto Institucional o Proyecto Educativo de Centro en el que se definen los objetivos que la organización aspira conseguir. En estas escuelas la propuesta programática se analiza, se discute y se contextualiza, existiendo algunos acuerdos colectivos que van más allá de la acción individual de cada docente.

La escuela donde se realizó el estudio presenta características que nos permiten ubicarla en este segundo estadio organizacional. Mediante la realización del diagnóstico, la elaboración, e implementación del plan de mejora, se aspiró a que el centro evolucionara al siguiente estadio: la organización que aprende.

Tercer estadio: la organización que aprende. Más allá de la existencia y realización de proyectos, las organizaciones que se encuentran en este estadio son capaces de institucionalizar los cambios. Esto exige la existencia de mecanismos de autoevaluación institucional y de un claro compromiso con el cambio. Como plantea Vázquez (2008), son organizaciones capaces de identificar y monitorear procesos puestos en marcha con relación a una innovación. Son centros que incorporan un plan de acción y donde la toma de decisiones se sustenta en la información que surge del registro y análisis de los datos proporcionados por actividades que tienen como propósito dar sustento al cambio.

Las organizaciones que aprenden son aquellas que facilitan el aprendizaje de todos sus miembros y continuamente se transforman a sí mismas. El desarrollo de la organización se basa en el desarrollo de las personas y en su capacidad para incorporar nuevas formas de hacer a la institución en las que trabajan. 
Cuarto estadio: organización que genera conocimiento. Corresponde al estadio más evolucionado y es posible alcanzarlo si se ha transitado por los estadios anteriores. En este tipo de organización el director no solo gestiona sino que lidera procesos de cambio. Vázquez (2008), establece que la institución que se encuentra en este nivel logra diseñar escenarios prospectivos para definir políticas a mediano y largo plazo, habiendo poco lugar para lo urgente e inesperado. Estos centros se caracterizan por promover procesos de investigación orientados al cambio, difundir experiencias exitosas y establecer sinergia con otros centros.

Nonaka y Taqueuchi (1999), plantean que las organizaciones exitosas son aquellas capaces de crear conocimiento y diseminarlo entre sus miembros. Este conocimiento es utilizado por aquellos que se encargan de desarrollar nuevas estrategias, empleándolo para crear productos útiles para afrontar los nuevos desafíos. Dentro de la organización, los analistas simbólicos son aquellos que están equipados con el conocimiento necesario para identificar, enfrentar y resolver nuevos problemas.

Los autores, señalan que hay dos tipos de conocimiento: el conocimiento explícito contenido en los manuales, informes, banco de datos, y el conocimiento tácito que se aprende solo mediante la experiencia; es personal, e incorpora la intuición y las nuevas ideas.

Tanto Senge (1992) como Nonaka y Takeuchi (1999) reconocen en Peter Drucker el pionero en acuñar la denominación "sociedad del conocimiento", definiéndola como aquella capaz de adquirir y aplicar conocimiento y postular que el conocimiento es un recurso más dentro de los factores de producción como la tierra, el capital y el trabajo.

Para crear conocimiento es necesario realizar la conversión del conocimiento tácito en explícito, logrando así que sea compartido con otros miembros de la organización. La creación de conocimiento organizacional comienza con la iniciativa de un individuo y la interacción que se da en el interior del grupo. El conocimiento se amplifica dentro del grupo a través del diálogo y la discusión, lo que permite generar nuevos puntos de vista dentro de los miembros del equipo. Esta interacción permite la transformación del conocimiento personal en conocimiento grupal, y luego organizacional.

Todos los miembros de una organización son responsables de la creación de conocimiento, independientemente de los roles. El trabajo más importante de los directivos y asesores consiste en guiar y conducir estos procesos de creación del conocimiento.

Los procesos de innovación pueden explicarse desde la teoría de creación de conocimiento organizacional. Nonaka y Takeuchi (1999), presentan la teoría de creación del conocimiento que responde a dos dimensiones: la epistemológica (del conocimiento tácito al explicito y viceversa) y la ontológica, que representa los diferentes niveles crecientes de conocimiento: individual, grupal, organizacional e interorganizacional. Cuando la interacción entre conocimiento tácito y explícito aumenta, aumentan los niveles de creación de conocimiento en un espiral ascendente. 
Figura 3

ESPIRAL DE CREACION DE CONOCIMIENTO ORGANIZACIONAL

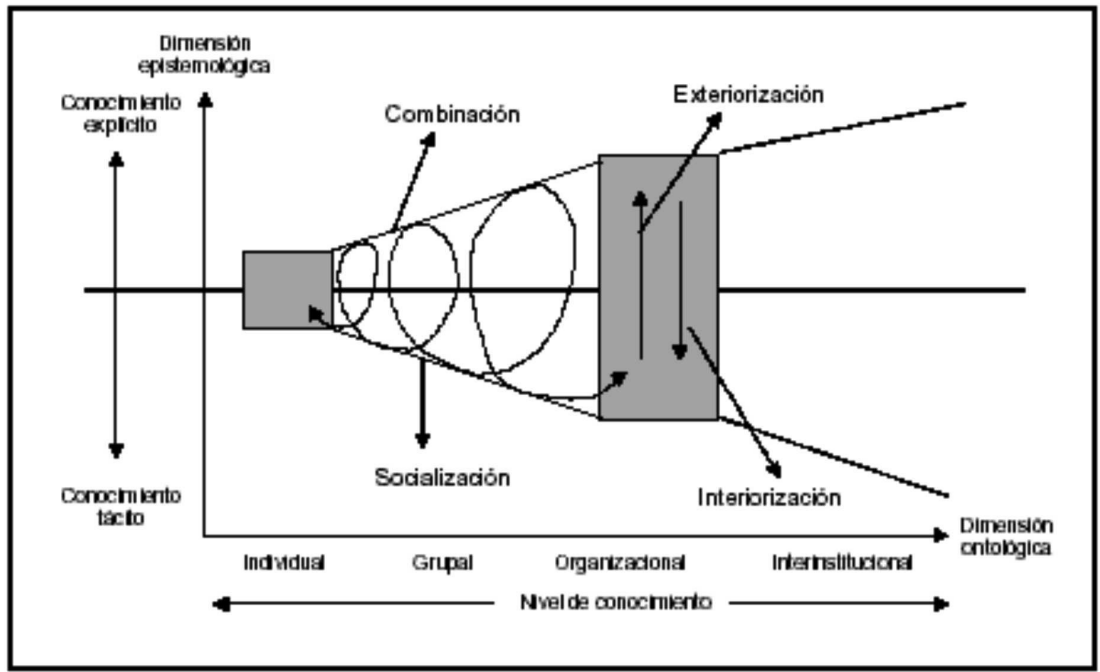

. Fuente: Nonaka y Takeuchi (1999: 83)

Resulta útil vincular estos procesos de conversión del conocimiento con las distintas actividades que hemos propuesto en el PMO para crear los puentes que unen el PEC, el PCC y la PA. Estos procesos se ven favorecidos cuando se ha desarrollado la capacidad de trabajar en equipo y generar una visión compartida (Senge, 1992).

Desplazarnos de una cultura individualista a una cultura colaborativa, implica conectar lo pedagógico a lo organizativo y para ello se necesitan profesionales capaces de trabajar en equipo y que asuman la acción colectiva como una condición ligada a la calidad educativa.

Rodríguez (2006: 37), pone atención a las principales dificultades en el desarrollo de procesos para la creación y gestión del conocimiento:

"Ausencia de objetivos claros para la gestión del conocimiento"

"Falta de planificación"

"Responsabilidad difusa: es recomendable definir un equipo de gestión del conocimiento dedicado especialmente al diseño, al desarrollo y a la evaluación del proceso"

"Contextualización: los proyectos de gestión del conocimiento no se pueden generalizar, deben diseñarse en función de las características de cada organización"

"Confusión conceptual: muchas organizaciones tienden a confundir la gestión de la información con la gestión del conocimiento"

"Falta de una cultura adecuada para la gestión del conocimiento"

Estas dificultades pueden comenzar a superarse mediante la implementación de estrategias y la movilización de recursos para la planificación educativa. El método y la prospectiva, por razones que definiremos a continuación, constituyen valiosas herramientas para la planificación educativa. 


\section{1.d. El método y la prospectiva como tributarios a la Planificación Educativa}

En las instituciones educativas, cuando se presenta un problema o se identifica algún aspecto sobre el que se quiere evolucionar, resulta necesario analizar sistemáticamente las diferentes alternativas de solución. Para poder elegir asertivamente qué hacer, es necesario tomar uno de los tantos caminos posibles para alcanzar la mejora.

Debemos considerar la importancia de "el método entendido como una poderosa herramienta para las estrategias de conocimiento y de acción, con la finalidad de organizar, ecologizar, globalizar y contextualizar los conocimientos y las decisiones" (Morin, 2003:11). El método es un camino que se crea y que se piensa; es una estrategia que se ensaya para llegar al final imaginado. El uso de un método adecuado nos permitirá "aprender a navegar en un océano de incertidumbres a través de archipiélagos de certeza" (Morin, 1999:11), preparándonos para poder captar las señales en el presente que van permitiendo avisorar el futuro.

Morin (2003), establece la diferencia que existe entre el método entendido como estrategia y programa, ya que los programas sirven poco ante situaciones cambiantes, inciertas y complejas. El programa constituye una organización predeterminada de la acción; necesita de condiciones estables para su ejecución, en tanto la estrategia sea abierta, permite avances y retrocesos, evoluciona, afronta los imprevistos y lo nuevo. "La estrategia... utiliza el alea" (Morin, 2003:32), expresión que hace referencia a las características de la estrategia que se despliega ante el azar, el riesgo y la incertidumbre.

Uno de los principios del método citados por Morin (2003) como guía para pensar lo complejo es el principio sistémico u organizacional que permite relacionar el conocimiento de las partes con el conocimiento del todo haciendo referencia a que el todo es más que la suma de las partes. En este punto Morin (2003) coincide con Senge (1992), cuando refiere a que esta es una característica de las organizaciones inteligentes: aquellas que han desarrollado la capacidad de aprender a aprender y de un pensamiento sistémico.

\section{1.e. La Planificación institucional}

Para avanzar en el desarrollo organizacional hacia los estadios superiores( organización que

aprende y que genera conocimiento) es preciso que la escuela adopte un modelo de planeamiento que lo posibilite.

Si buscamos un cambio orientado a la mejora, habremos de preguntarnos cómo hacer para que se modifiquen las estructuras del centro escolar: redefinir objetivos con relación al trabajo de los docentes; los contenidos de la enseñanza, la propuesta didáctica desarrollada en las aulas y la incorporación de las Tecnologías de la Información y la Comunicación (TICs), entre otros aspectos.

Para que el cambio sea posible, es necesario impulsar nuevas maneras de organizar y gestionar las instituciones, para abrirlas a la innovación (Lugo, 2009).

El paradigma clásico de planificación educativa corresponde a la planificación normativa, que se caracteriza por ser una propuesta con que se responde a un deber ser, sin contemplar la realidad, ni los avatares lógicos del proceso necesario para lograr las metas propuestas. En muchas escuelas aún predomina este modelo de organización y gestión, caracterizado por la falta de adaptabilidad y por un fuerte apego a lo conocido e instituido. Esta manera de funcionamiento no permite atender adecuadamente a las nuevas demandas. 
En la crisis del planeamiento tradicional surge la perspectiva situacional, que se concreta en el Planeamiento Estratégico Situacional desarrollado por el economista chileno Carlos Matus quien estructuró el marco conceptual y metodológico de esta nueva forma de planificar. “... no basta la sola formulación de una estrategia de desarrollo explícita o implícita para que la planificación encuentre su cauce positivo. Es necesario, además, que esa estrategia adquiera las connotaciones dinámicas de una coyuntura favorable e implique ciertos cambios con respecto al marco tradicional ..." (Matus, 1993:63).

Los desafíos para el nuevo modelo son: el dominio de habilidades para crear y seleccionar información, disponer de cierta autonomía, flexibilidad, capacidad para tomar decisiones y para resolver problemas.

Al decir de Aguerrondo (2002), el éxito del PES, está en que sea capaz de servir como "hoja de ruta", una herramienta que guía atravesando todas las áreas y dimensiones de la organización.

Planificar permite la construcción de la imagen de lo deseable: el futuro desde el presente, y reflexionar sobre el presente resulta imposible sin acudir al pasado, pues en éste encontró su nacimiento el tiempo en que vivimos (Gimeno Sacristán y Pérez Gómez, 2008).

EI PES es un proceso para intervenir y transformar la realidad, no solo para analizarla y diagnosticarla. Ofrece la posibilidad de aumentar la autonomía en las escuelas, el aprendizaje organizacional y el de los docentes; para ello se hace necesario desarrollar la capacidad de aprender a aprender.

Castillo (2000), destaca las siguientes características de PES:

- Para el PES el planeamiento es un proceso de reflexión que precede y preside la acción

- Todos los actores planifican, pero con diversos grados de sistematicidad.

- El Problema es el concepto central del PES: en este tipo de planificación no se parte de objetivos, sino de la identificación, jerarquización, elección y delimitación del problema

- El concepto de Momento: a diferencia del planeamiento tradicional el cual define etapas secuenciadas de forma lineal, comienza por el diagnóstico, pasa por el diseño, aprobación, ejecución y terminando con la evaluación del plan, el PES hace uso del concepto de "momento" entendido como instancia o circunstancia por la que atraviesa un proceso que no tiene comienzo ni fin definido.

La PES permite conducir la organización en procesos turbulentos. Incorpora el contexto, empieza definiendo el problema de manera precisa y operativa con relación al cual se arma el proyecto. Una vez identificados los objetivos, estos se vuelven guías para la acción.

Definida la imagen-objetivo que se desea alcanzar a partir de la situación real en la que se encuentra la organización, se establecen metas, recursos y plazos para lograrla, pero se tiene en cuenta permanentemente cómo deben ir adaptándose las metas y los plazos a las dificultades que presenta todo intento de transformación (Figura 4).

Alcanzar la imagen -objetivo no es un proceso lineal; nos marca el rumbo que puede redefinirse en función de las diferentes situaciones que se van dando en una serie de avances y retrocesos que configuran un proceso que puede representarse con una espiral ascendente. Se considera fracaso solo si a lo largo del tiempo no se avanza en nada hacia la imagen- objetivo. 
Figura 4. Planeamiento Estratégico Situacional en la práctica

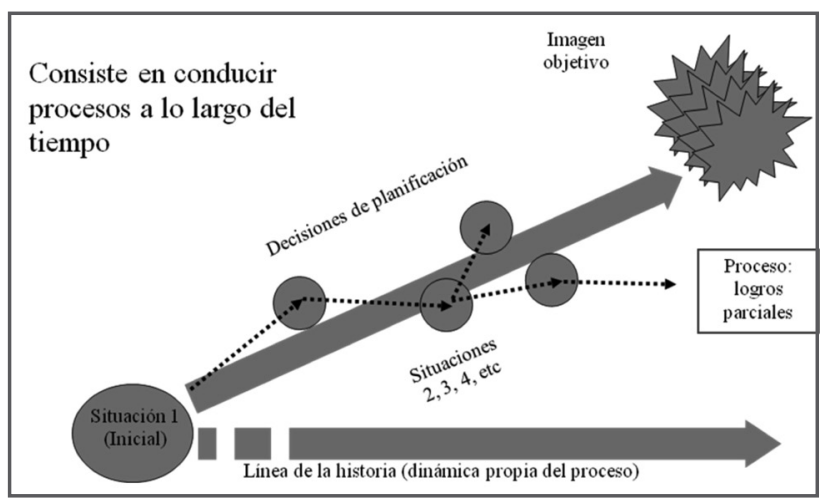

Fuente: Lugo y Sampedro (2009:34)

En todo momento se lleva adelante un seguimiento organizacional, evaluando procesos y resultados e incorporando los cambios como parte del trabajo cotidiano.

\section{1.f. La escuela se proyecta: puentes para fortalecer la articulación entre Planificación institucional y Planificación de aula}

Planificar nos permite sistematizar nuestra intervención como profesionales. Según Antúnez (1997), los instrumentos fundamentales para la planificación del centro escolar son el Proyecto Educativo de Centro (PEC), el Proyecto Curricular de Centro (PCC) y la Planificación de Aula (PA).

Por su parte los Proyectos de Mejora Organizacional (PMO) que articularán con los anteriores, son como proyectos satélites que los acompañan, sitúan y actualizan, a modo de grúas nodrizas para la gestión eficaz y eficiente.

La palabra proyecto, según la RAE (2001), refiere al "pensamiento de ejecutar algo", "pensamiento en perspectiva", "mirar hacia adelante". Trabajar con proyectos significa entrar en el territorio de la prospectiva, ya que implica movimientos hacia un futuro deseable.

En lo que refiere a las instituciones educativas, se trata de pasar de un saber espontáneo o intuitivo (no sistematizado ni explícito), a un saber que se materializa en un proyecto que se construye desde una actividad consciente, explícita y profesional.

Un buen proyecto es aquel que pone en su lugar lo que debe permanecer y lo que debe cambiar, e involucra a los actores y a los destinatarios de la institución, generando en los primeros un compromiso y una responsabilidad por los resultados obtenidos. A esta responsabilidad por los resultados, Bryk y Driscoll (1988) la denominan ética de cuidado.

1.f.a. El primer puente: entre el Ideario y el Proyecto Educativo de Centro. EI PEC y las dimensiones de la organización escolar

Gimeno Sacristán y Pérez Gómez (2008), plantean que para realizar cambios en el sistema educativo en un sentido amplio y en profundidad hay, que apuntar al funcionamiento interno de los centros escolares. Para ello es necesario otorgarles cierto grado de autonomía con el fin de que puedan adaptar, concretar y contextualizar el currículum que en ellos se imparte. En el encuadre de una tendencia descentralizadora se genera un espacio de autonomía relativa que da paso a innovaciones cualitativas llevadas adelante por los equipos de maestros y directores con el objeto de organizar un proyecto propio (PEC) que conduzca a una mejora de los resultados.

En esta situación es posible atender más específicamente a las necesidades de cada 
comunidad, elegir actividades culturales adecuadas para cada centro escolar e involucrar a directivos, docentes, alumnos y padres, en su co-construcción y ejecución.

Antúnez (1997:20), señala que el PEC debe ser el primer paso dentro de la planificación escolar, ya que constituye un eje vertebrador y una referencia básica para toda la comunidad educativa. Se trata de "una propuesta integral que permite dirigir coherentemente el proceso de intervención educativa en una institución escolar".

En él se definen los rasgos de identidad; se plasman los objetivos generales y la estructura organizativa del centro. Los objetivos deben ser claros y elaborados a partir de criterios compartidos por los miembros de la escuela a partir de acuerdos: ideológicos, filosóficos, organizativos, metodológicos y didáctico-pedagógicos.

Es importante verificar si existe coherencia interna entre los principios declarados en el Ideario de la escuela y los que figuran en el PEC, así queda tendido el primer puente sobre el cual se puede comenzar a concretar el currículum.

Frigerio y Poggi (1999), nos presentan y caracterizan las dimensiones del campo institucional que habrán de considerarse y articularse en la elaboración del PEC. Ellas son: la dimensión administrativa, organizacional, didáctico-pedagógica y comunitaria. Para Tejera (2003), las dimensiones del campo institucional constituyen potentes analizadores del centro escolar.

Por su parte, Farneda (2000), plantea que el PEC será el resultado de una visión compartida que debe construirse desde la participación; esa implicación es lo que favorece el pasaje sustancial de la neutralidad al compromiso y responsabilidad, por los resultados obtenidos en cada escuela.

El autor, hace referencia a las posibilidades que otorga el PEC para romper con la homogeneidad de los planteos que se asumen desde la administración, y atender a la diversidad. En especial invita a los colegios católicos a pensar el PEC "en pastoral" y no "con pastoral".

Uno de los grandes desafíos para las organizaciones educativas consiste en asegurar la transposición de los objetivos, principios y actividades declarados en el proyecto, a la vida de la organización y del aula.

\section{1.f.b. El segundo puente: entre el PEC y EI Proyecto Curricular de Centro}

"La actividad de diseñar el currículum se refiere al proceso de planificarlo, darle forma y adecuarlo a las peculiaridades de los niveles escolares. Desde las declaraciones de finalidades hasta la práctica, es preciso planificar los contenidos y las actividades con cierto orden para que haya continuidad entre intenciones y acciones" (Gimeno Sacristán y Pérez Gómez, 2008:224)

A partir del currículum de Educación Inicial y Primaria (ANEP-CEP, 2008), que define la Administración Nacional de Educación Pública y de los objetivos generales y orientaciones del PEC, es tarea del equipo docente realizar las precisiones en relación a qué, cómo y cuándo hay que enseñar y evaluar, tomando las decisiones de orden didáctico- pedagógico más adecuadas para cada escuela.

Es a los docentes a quienes les corresponde llevar adelante el desarrollo curricular, realizando opciones metodológicas y realizando los acuerdos necesarios en cuanto cómo desarrollar las actividades de enseñanza y aprendizaje de manera exitosa, configurando así un estilo educativo propio de la escuela que habrá de plasmarse en un documento: el Proyecto Curricular de Centro (PCC).

Gimeno Sacristán y Pérez Gómez (2008:287), destacan la importancia de "la coordinación como un espacio de diseño curricular" ya que permite explorar las conexiones entre los saberes, seleccionar nuevos recursos didácticos, leer y reflexionar para la actualización disciplinar, 
evitando la rutinización de las prácticas. Así los docentes son verdaderos constructores del currículum (Domingo, 2005).

Cuando esto no sucede, Gimeno Sacristán y Pérez Gómez (2008), nos señalan cómo al caer en una actividad docente aislada, es muy probable que la forma que se le da a lo curricular quede en manos de las editoriales, cuando en los libros de texto directa o indirectamente presentan los contenidos de las asignaturas, su secuenciación y su profundización restándole al docente la tarea de la temporalización de contenidos y de la evaluación. EI PCC es un instrumento dinámico para la formación permanente de los maestros tanto a nivel individual como colectivo y está fuertemente enlazado con la Planificación de Aula.

\section{1.f.c. El tercer puente: entre el PCC y La Planificación de Aula}

Ciertamente el aula es un espacio recortado y privilegiado para la acción intencional en torno a la enseñanza y aprendizaje de lo disciplinar; pero se obtienen mejores resultados si los maestros desarrollan la capacidad de compartir y relacionar lo que están haciendo en sus clases con lo que hacen otros docentes.

El puente que se extiende entre el PCC y la planificación de aula, es de doble sentido y muchas veces un punto de clivaje en la planificación de la escuela. La planificación de aula constituye el último y primer escenario de concreción curricular. Aquí se define qué se enseña, cuándo, cómo, con qué actividades y cómo se va a evaluar. Es en este último eslabón que muchas veces aparecen tensiones entre teoría y práctica, entre lo que pensamos y lo que hacemos, y donde se juega la calidad de los aprendizajes y el logro de los resultados esperados para el alumnado.

La figura 5 muestra las relaciones entre los diferentes niveles de concreción del currículum e ilustra la importancia de realizar una planificación en cascada, para asegurar la coherencia interna entre los documentos de la escuela y las acciones que estos persiguen, vinculando la teoría de la propuesta escrita en los documentos, con la práctica que se desarrolla en el aula.

Este espiral dialéctico muestra, por un lado, la cascada descendente que busca asegurar la articulación del objetivo general del ideario que describe una visión amplia del quehacer educativo orientado hacia la persona a formar, con los objetivos generales y específicos del PEC.

El siguiente eslabón enlaza las intenciones del área didáctico- pedagógica del PEC con el PCC elaborado a partir de el/las Área/s de Conocimiento (Matemático, de Lenguas, de la Naturaleza, Social, Corporal) que resulte necesario atender en función del diagnóstico de situación de partida de los niños. El último eslabón pretende reforzar la articulación de todas estas acciones con la PA.

Figura 5. Espiral dialéctico de los diferentes niveles de concreción de la planificación en la escuela

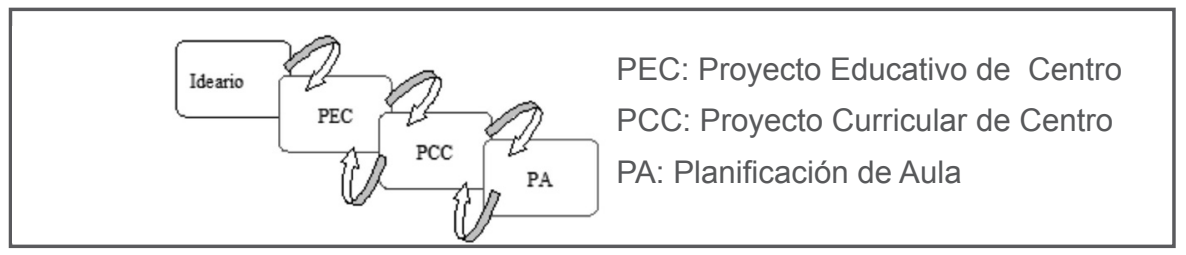


Por otra parte debemos atender a la recuperación y socialización de las buenas prácticas que los docentes realizan en forma individual y a la identificación de los modelos de enseñanza y aprendizaje que sustentan las prácticas, lo que resulta fundamental para poder generar rutinas guiadas por la reflexión didáctica de los docentes. Una vez transitada esta etapa se podrán hacer acuerdos metodológicos que permitan la elección consensuada de alguna estrategia didáctica específica para esa escuela, planificando en función ella actividades áulicas. Estos aspectos permitirán modificar y resignificar el PCC y el PEC (como muestran en el esquema las flechas ascendentes), convirtiéndolos en documentos vivos y contextualizados con relación a la demanda actual de la escuela. Estas acciones que permiten generar conocimiento sobre la escuela, favorecerán el desarrollo organizacional.

1.f.d. La planificación de aula: cómo asegurar que la enseñanza favorezca el aprendizaje ¿Cómo garantizar que los alumnos aprendan asegurando el derecho a la educación de calidad para todos y todas?

Partimos del supuesto de que no siempre que enseñamos hay aprendizaje, por lo tanto es necesario identificar qué situaciones de enseñanza favorecen el aprendizaje. Aprender es construir un conocimiento mediante un proceso en el que existe una interacción entre el nuevo conocimiento y el que el alumno ya tiene.

El maestro con su profesionalismo habrá de seleccionar las teorías de enseñanza y de aprendizaje y los saberes específicos de las asignaturas, para poder transponer el conocimiento científico en conocimiento académico, partiendo del conocimiento vulgar o ideas previas del alumnado (Antúnez, 1997).

Movilizar y en ocasiones reestructurar esas ideas previas no es sencillo. Con el equipo que trabajó en el proyecto de mejora para la escuela donde se realizó la investigación, nos posicionamos desde la teoría de la Enseñanza para la Comprensión (Blythe, 1999).

Blythe (1999), desarrolla el marco conceptual de esta teoría, tomando como referencia los aportes realizados por Gardner y Perkins (1972-2000), a través del proyecto "Cero". Su planteo coincide con lo que Morin (1999), definió como comprensión intelectual. Se les llama actuaciones de comprensión a aquellas que le permiten a los alumnos, además de entender la información, ampliarla y aplicarla a nuevas situaciones; conectar lo aprendido en la escuela con las actividades fuera de ella. De esta manera las experiencias de aprendizaje serán permanentes, coherentes y significativas.

La enseñanza para la comprensión se basa en las configuraciones didácticas que tienen en cuenta las ideas previas de los alumnos y sus procesos de aprendizaje apuntando a las prácticas metacognitivas. Por configuraciones didácticas entendemos: "la manera particular que despliega el docente para favorecer los procesos de construcción del conocimiento" (Litwin, 2008: 97).

Por su parte Dibarboure (2007), nos presenta dos modelos para explicar las formas de aprender: el modelo de procesador y el modelo conexionista.

El modelo de procesador supone considerar al ser humano como un computador que procesa información; este modelo ha permitido estudiar en psicología cognitiva las funciones de percepción, atención, memoria, lenguaje y razonamiento y nos permite comprender por qué los alumnos olvidan algunos conceptos ya que hay una memoria a corto y largo plazo.

El modelo conexionista está basado en el funcionamiento del cerebro a través de las redes neuronales que se van construyendo y reconfigurando en la medida que aprendemos. 
Dibarboure (2007) ha elaborado un modelo para representar el concepto de redes semánticas que se ilustra en la figura 6. Los conceptos representados como nodos o esferas, están vinculados unos con otros, formando un sistema de relaciones. Cuando el sujeto aprende se establecen nuevas conexiones de modo que el nuevo concepto debe quedar unido a la red conceptual existente a través de una nueva relación (representadas con líneas). Si el concepto no queda integrado a la red, se pierde, se olvida. Esto requiere de la habilidad del docente para generar situaciones de aprendizaje que permitan la creación del vínculo conector y de la motivación del alumno lo que permitirá la activación para la integración del concepto.

\section{Figura 6. Representación del modelo conexionista.}
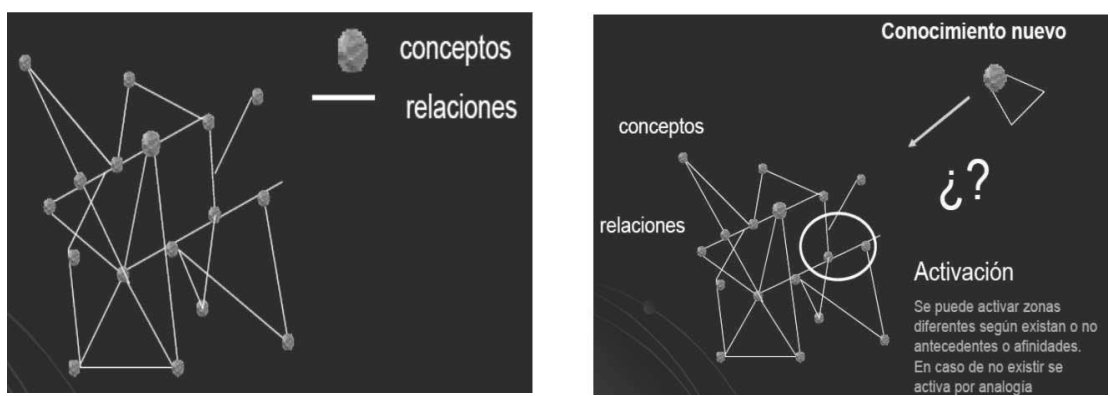

Fuente: Dibarboure (2007: 142-143).

Este modelo nos permite explicar que todos los alumnos están en condiciones de aprender más allá del contexto y de su historia previa. Cada uno ingresa a la escuela con una red conceptual diferente y para los educadores es un desafío implementar diferentes estrategias para generar experiencias de aprendizaje que permitan incorporar los nuevos conocimientos para alcanzar los objetivos curriculares del nivel.

\section{1.g. Diagnóstico organizacional}

Para evaluar la situación en que la organización se encuentra, generando la información a partir de cuyo análisis se podrán descubrir las potencialidades y fortalezas e identificar las debilidades y áreas críticas que deberán ser afrontadas para dar solución a los problemas detectados.

Rodríguez (2006), establece que el diagnóstico corresponde a un esfuerzo de conocimiento en el que en base a los datos e información disponible se buscan criterios para volver relevantes algunos aspectos de la organización, mientras otros pasan a constituir un trasfondo.

Rué (1999), define la importancia de la autoevaluación institucional que refiere a la evaluación interna de la escuela, e informa de un proceso surgido de la necesidad de reflexionar desde el propio contexto por parte de los agentes involucrados en él y sobre el valor y alcance de las actividades desarrolladas. Estos aspectos diferencian a la autoevaluación institucional de toda forma de evaluación externa, la cual constituye un proceso de regulación propia de las escuelas que aprenden y generan conocimiento sobre sí mismas.

Para Murillo (2008), la autoevaluación institucional surge como respuesta y como una vía para la mejora de los centros educativos y constituye un camino para dar cuenta de sus resultados y también de sus procesos. 
Figura 7. El diagnóstico y las fases del PMO en las etapas del proceso de innovación

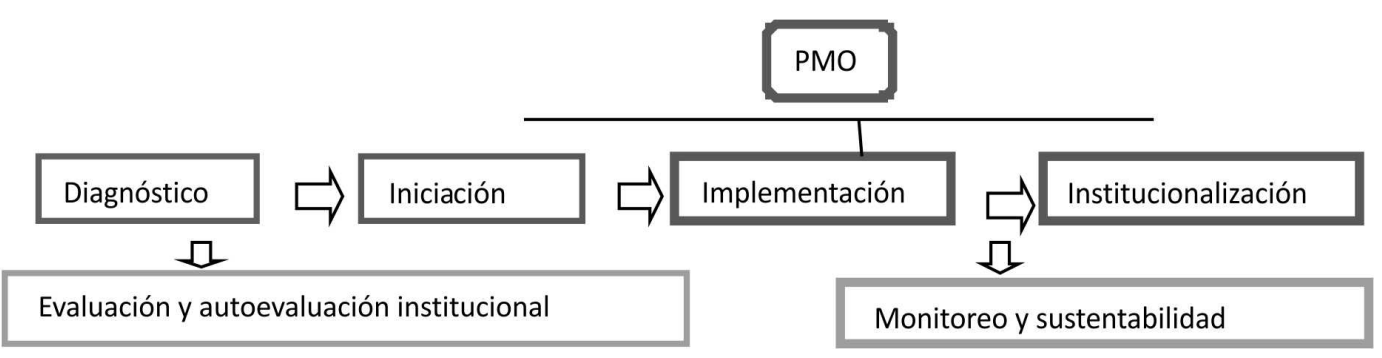

Como muestra la figura 7, el diagnóstico debe formar parte de un proceso; es el inicio de un cambio. Luego de definido el problema, se realiza el diseño del Plan de mejora en el que se reconocen distintas fases: iniciación; implementación o puesta en práctica del cambio, e institucionalización (Vázquez, 2008).

\section{1.h. El Proyecto de Mejora Organizacional (PMO)}

Para Cantón Mayo (2004), el PMO, es un instrumento a través del cual se planifican, desarrollan y evalúan los cambios e innovaciones en los centros educativos, con la finalidad de mejorar la calidad de los aprendizajes desde una perspectiva práctica y contextual.

Para todo PMO es necesario definir los dispositivos de seguimiento del proceso de cambio (monitoreo) y generar sustentabilidad, esto es crear las condiciones para que el centro siga cambiando (Guarro, 2005). Monitorear estos procesos resulta fundamental para introducir los ajustes oportunos para el logro de los resultados esperados.

Es aconsejable la realización de protocolos para la aplicación de los instrumentos. Así cada instrumento de monitoreo será acompañado de un instructivo de uso con algunas recomendaciones. Para cada dispositivo se establece quién, cuándo y cómo lo aplica, junto a una descripción que orienta sobre el análisis de la información recogida.

Para optimizar los resultados es necesario organizar, articular y secuenciar los aspectos relacionados con la planificación del cambio, para elevarlo del nivel intencional al plano operativo (Vázquez, 2007).

Los componentes del PMO son: 1. Definición de Objetivos: general y específicos (priorizados y seleccionados). 2. Actividades y procedimientos: concretarán las acciones de los objetivos. 3 . Metas: indicadores de avance 4. Responsables: personas encargadas de realizar las acciones previstas. 5. Recursos y apoyos: materiales y personales. 6. Diagrama Gantt: cuándo se van a realizar las acciones previstas. 7. Presupuesto 8. Evaluación, diagnóstica: de proceso y final del proceso de mejora.

\section{1.i. Director, liderazgo, resistencias y gestión exitosa del cambio}

Una de las principales amenazas en los proceso de cambio emergen del propio centro educativo, y son las resistencias que surgen por el miedo a perder la seguridad que proporciona lo ya conocido.

Para Álvarez en Villa Sánchez (2008), la actitud del director es fundamental para facilitar u obstaculizar el cambio. El estilo de liderazgo para gestionar un centro con éxito depende en buena medida de la inteligencia emocional del director, de las capacidades de empatizar; de crear y promover redes de relaciones; de reforzar y destacar lo positivo; de argumentar 
con conocimiento de causa; de crear equipos con espíritu colaborativo; de la adaptabilidad al cambio; de mediar los conflictos y de autoconciencia de sus capacidades y limitaciones. El autor afirma que existe una fuerte correlación entre el liderazgo pedagógico, distribuido y transformador con los logros en los resultados de los alumnos y que inevitablemente impacta el desarrollo organizacional.

\section{1.j. Rol del asesor en los procesos de mejora}

Las iniciativas innovadoras de los grupos aislados de profesores suelen disolverse si no existen apoyos, estructuras de soporte o elementos mediadores. Hoy emerge una visión didáctica del asesoramiento desde un enfoque de colaboración crítica o de proceso. Una de las acepciones de la palabra asesor hace referencia a las personas externas a la institución que ofrecen un consejo profesional.

Domingo (2005), plantea entender el asesoramiento desde una perspectiva curricular, considerando al centro como comunidad básica de cambio. Parte de una visión estratégicodialéctica en torno a los procesos de mejora, que surgen como procesos colaborativos en una comunidad de aprendizaje. Estos procesos implican: autorevisión de la práctica; identificación, priorización y selección de ámbitos de mejora; diseño de un plan de acción; su puesta en práctica, monitoreo y evaluación, retroalimentación y selección de nuevos focos de trabajo.

El asesor, al integrarse al equipo del que forman parte los docentes como constructores de currículum, también él lo termina haciendo, promoviendo el desarrollo curricular y la reapropiación de la práctica profesional. Asumir esta responsabilidad implica romper con la separación entre teoría y práctica, y favorecer la transposición didáctica.

Resulta fundamental apuntar a los docentes y directivos como profesionales de la educación para que ellos en la realidad de su escuela identifiquen lo que es necesario mejorar, fortalecer o trabajar en equipo, apropiándose del proceso de mejora sin depositar exclusivamente esta tarea en el asesor. El asesor trabaja "con" en lugar de intervenir "en".

Por su parte María de Mar Rodríguez en Domingo (2005), establece las diferencias básicas entre el rol del asesor y el del inspector. Destaca la misión del asesor vinculada fuertemente a la formación permanente, ya que parte de la misma consiste en destinar un tiempo para definir conceptos; aportar información oportuna, actualizada y científica; seleccionar textos, autores, generar univocidad, de modo que ese saber acordado y compartido otorgue a los docentes un nuevo saber. Ofrece un apoyo entre colegas desde la horizontalidad, rompiendo con el modelo piramidal jerárquico y promoviendo el liderazgo de los verdaderos responsables del centro. De esta manera se instala la consolidación de una cultura de aprendizaje.

Por otra parte, desde el primer momento en que el asesor toma contacto con los miembros de la organización, debe explicitar dos aspectos que caracterizan su accionar y que conforman en parte su ética profesional: la discrecionalidad y la confidencialidad con respecto al manejo de la información obtenida al relevar y analizar los documentos que requieran reserva.

\section{Metodología y técnicas utilizadas para el diagnóstico}

En el presente trabajo de investigación hemos utilizado una metodología de corte cualitativo. Las decisiones que nos han llevado a la elección de este enfoque se deben; por un lado, a la naturaleza del objeto de estudio e indagación (relacionado a diferentes aspectos que se abordan desde la gestión en un colegio a nivel de primaria) y por otro, a los aportes epistemológicos y teóricos que provienen del paradigma fenomenológico. 
El enfoque fenomenológico centra su atención en el significado que las situaciones tienen para las personas involucradas en la investigación. El investigador participa en la dinámica habitual de los integrantes del grupo que se indaga, capturando los hechos en su contexto. El enfoque de esta metodología es holístico, global, intenta comprender la realidad abarcándola en su totalidad y no de manera fragmentada.

Esta perspectiva metodológica nos permite describir e interpretar los fenómenos sociales y por lo tanto educativos, que constituyen un complejo mundo al que nos aproximamos para descubrir cómo las personas vivencian, experimentan, interpretan y construyen los significados del mundo social y cómo éstos se integran al lenguaje, cultura y acciones de los actores, con la finalidad de desarrollar una construcción de la realidad en un contexto particular (Latorre, 2005).

El autor plantea que los resultados de este tipo de investigación son creados, más que descubiertos. Son creados basándose en la interacción, interpretación y síntesis entre los participantes y el investigador, reconstruyendo activamente la situación en torno a la cual se hace foco.

Con relación a esto último, Rodríguez Gómez (1999), aporta que en el proceso de investigación cualitativa no existe linealidad entre los momentos de definición del problema, formulación de las preguntas que orientan la investigación, recogida de datos y contrastación con el análisis de los mismos para descartar o confirmar los supuestos, redacción de informe con los hallazgos, sino que más bien se trata de un proceso dialéctico y espiralado, ascendente, recurrente, inductivo y deductivo que permite al investigador arribar a una comprensión global del problema y actuar en consecuencia.

Según la tipología de estudios de casos planteada por el mismo autor, podemos clasificar nuestro caso como microetnográfico y situacional. Microetnográfico porque aborda un nivel específico dentro de una organización, y situacional, porque el estudio se realizó desde la perspectiva de los que han participado en el mismo.

Vázquez (2007), presenta la utilidad del estudio de casos en la enseñanza, con fines de investigación y pedagógicos; la autora destaca la fortaleza de esta metodología ya que permite reconocer, registrar, documentar y hacer visibles las prácticas que resultan valiosas para el colectivo, efectivizándose el proceso de socialización de las mismas.

Por ello, constituye un potente dispositivo para promover la reflexión y el análisis crítico en los centros educativos, favoreciendo el aprendizaje organizacional en la medida que se lo integre a las prácticas de gestión institucional.

\section{2.a. Las técnicas}

Resulta sustancial definir, elaborar y realizar el pre- test de las herramientas y las técnicas que vamos a utilizar. La selección de las mismas se realizó en función de su pertinencia para recoger los datos. Como plantea Bernal (2006:117), "es importante considerar que no hay técnicas autosuficientes para la comprensión de la realidad de ningún aspecto u objeto de estudio por lo que es necesaria la complementariedad de las mismas".

Las técnicas utilizadas fueron la entrevista en profundidad, cuestionario semi- estructurado (por tener preguntas abiertas y cerradas) y análisis de documentos, que han sido trianguladas con el marco teórico para el abordaje del problema.

\section{2.b. El análisis}

Para comenzar a trabajar en un caso es necesario elaborar un diseño de investigación. Para Sautu (2003), en el diseño confluyen teoría, metodología y técnicas. Latorre (2005), plantea que 
la triangulación es un recurso típico de la metodología cualitativa, que consiste en contrastar una serie de fuentes para confirmar datos e interpretaciones con relación a un determinado objeto de estudio. Este procedimiento garantiza fiabilidad y otorga rigor científico ya que la biografía y subjetividad del investigador también están en juego.

Con la presente investigación se pretendió comprender la realidad de la escuela para poder actuar y mejorar sus prácticas. Analizar implica, al decir de López Yañez (2002: 28), “...pasar lo que denominamos realidad -los hechos- por un tamiz; a ese filtro lo llamamos teoría."

Para el análisis se efectuó la triangulación de los datos provenientes de las entrevistas exploratorias, de los documentos, de los cuestionarios y del marco teórico. Durante el análisis se realizaron comparaciones; se buscaron relaciones y evidencias, se procesaron interpretaciones y descripciones, lo que nos condujo a la síntesis.

\section{Presentación de resultados y conclusiones}

En este apartado presentamos los principales hallazgos obtenidos a partir del Diagnóstico Organizacional y el Plan de Mejora.

\section{3.a. El Diagnóstico}

En una primera instancia para la realización del diagnóstico pasamos por dos momentos: el primero relacionado a la recolección de datos para la identificación de la demanda; aquí se realizaron entrevistas exploratorias y la recopilación de documentos y antecedentes institucionales; el segundo momento correspondió al análisis de los datos recogidos y en esta ocasión se aplicaron como técnicas complementarias para profundizar en la comprensión del problema; el cuestionario y el análisis de documentos.

En una segunda instancia, se reconocieron las necesidades a través de la identificación de las fortalezas, debilidades y prioridades de la escuela, para finalmente, basándose en la sistematización de la información, llegar a establecer acuerdos con la organización.

En el siguiente cuadro se detalla para cada fase del diagnóstico: características, técnicas utilizadas y momentos de aplicación.

\section{Cuadro 1. Plan de trabajo}

\begin{tabular}{|c|c|c|c|}
\hline FASE & MOMENTO & CARACTERÍSTICAS & TÉCNICAS \\
\hline $\begin{array}{l}\text { Fase } 1 \\
\text { Identificación de la } \\
\text { demanda }\end{array}$ & Mayo- Junio & $\begin{array}{l}\text {-Etapa exploratoria. } \\
\text {-Antecedentes institucionales. } \\
\text {-Identificación de actores y sectores } \\
\text { implicados. } \\
\text {-Recopilación documental. }\end{array}$ & $\begin{array}{l}\text {-Entrevistas en } \\
\text { profundidad. } \\
\text { - Análisis documental. }\end{array}$ \\
\hline $\begin{array}{l}\text { Fase } 2 \\
\text { Comprensión del } \\
\text { problema }\end{array}$ & Junio- Julio & $\begin{array}{l}\text {-Pre-test del cuestionario } \\
\text { autoadministrado. } \\
\text {-Identificación de aspectos implícitos } \\
\text { / explícitos. } \\
\text {-Rastreo de antecedentes (teóricos, } \\
\text { investigaciones relacionados con el } \\
\text { tema) }\end{array}$ & $\begin{array}{l}\text {-Cuestionario } \\
\text { autoadministrado. } \\
\text {-Análisis de } \\
\text { documentos: ideario, } \\
\text { Proyecto de Centro, } \\
\text { programa oficial de } \\
\text { Primaría, página web. }\end{array}$ \\
\hline $\begin{array}{l}\text { Fase } 3 \\
\text { Reconocimiento de } \\
\text { necesidades }\end{array}$ & Julio- Agosto & $\begin{array}{l}\text {-Identificación de fortalezas y } \\
\text { debilidades. } \\
\text {-Definición de prioridades. } \\
\text {-Dimensiones involucradas en } \\
\text { proceso de mejora. } \\
\text {-Determinación de personas } \\
\text { implicadas en la elaboración delPMO. }\end{array}$ & $\begin{array}{l}\text { Reunión(es) de trabajo } \\
\text { con equipo de gestión. }\end{array}$ \\
\hline $\begin{array}{l}\text { Fase } 4 \\
\text { Acuerdos con la } \\
\text { organización }\end{array}$ & Agosto & $\begin{array}{l}\text {-Sistematización de la información. } \\
\text {-Redacción del Informe. } \\
\text { - Integración del equipo de trabajo } \\
\text { para el plan de mejora. }\end{array}$ & \\
\hline
\end{tabular}




\section{3.a.a. Fase 1. Identificación de la demanda}

Con los datos recogidos en las entrevistas exploratorias se construyó la matriz de análisis. La matriz es un instrumento de análisis que nos permitió relacionar las dimensiones organizacionales, (Frigerio, 1999) con los principales problemas identificados por los entrevistados.

El proceso continuo en espiral ascendente de recogida de información y análisis de los datos, nos ha permitido ir construyendo las percepciones teóricas en relación al tema que justifica con el estudio, y se identificó la demanda. Así llegamos a la primera aproximación al problema, a la determinación de los posibles factores causales y la identificación de las dimensiones organizacionales más fuertemente involucradas con el mismo.

Como se puede ver en el modelo de análisis que se presenta a continuación, la dimensión más fuertemente implicada es la Organizacional, siguiéndoles la Administrativa y la Didácticopedagógica. Los sectores involucrados corresponden a Dirección General, Dirección de Primaria, Administración y Docente.

Figura 8. Modelo de Análisis

\begin{tabular}{|c|}
\hline PROBLEMA \\
Dificultades en la planificación institucional en Educación \\
Primaria y su articulación con la planificación de aula
\end{tabular}

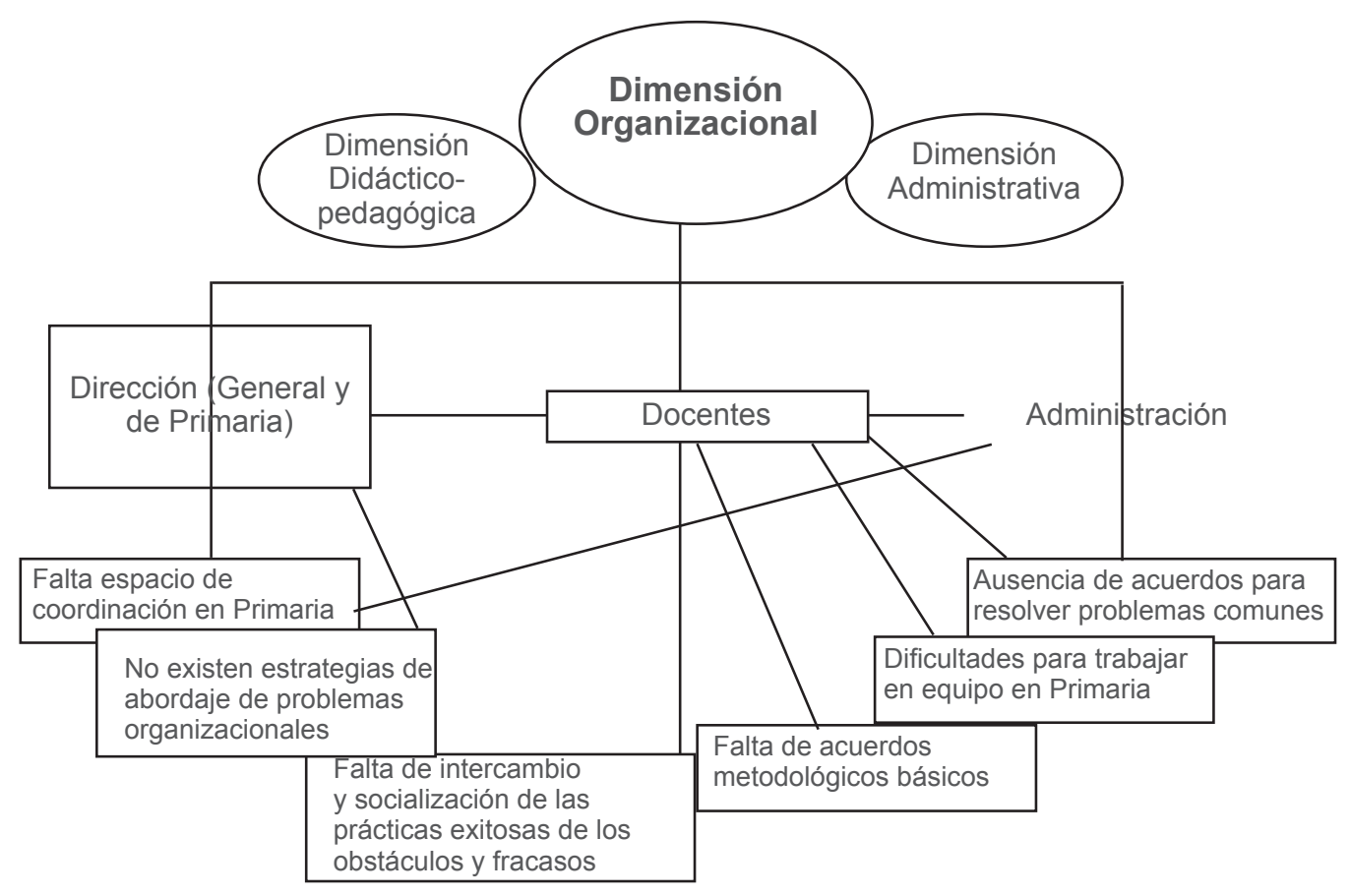


Las "Dificultades para articular la planificación institucional en Educación Primaria con la planificación de aula" han estado presentes al menos desde que la Directora oc upa ese cargo (cuatro años). No se constató la existencia de antecedentes institucionales en el abordaje de esta problemática. Tampoco hemos encontrado antecedentes de procesos de mejora a partir de proyectos en el colegio.

\section{3.a.b. Fase 2. Comprensión del problema}

En la segunda etapa, para la comprensión del problema, surgió la necesidad de profundizar en la identificación de elementos relacionados con el proyecto educativo de centro; la tarea en la clase; a los temas que el cuerpo docente considera prioritarios para su abordaje a nivel de la organización y del aula; y la detección de los aspectos que desearían cambiar para el logro de mejores resultados en la escuela. Para ello se diseñó el cuestionario autoadministrado y se realizó el pre- test del mismo.

\section{3.a.c. Fase 3. Identificación de necesidades}

Para identificar las necesidades se utilizó la Técnica del Iceberg. El iceberg (Tejera, 2003 citando a Vandenberghe y Staessens, 1991; Schein, 1990) es un analizador de la cultura institucional que permite conocer, a partir de lo observable y explícito, las prioridades de la organización e inferir las lógicas que subyacen en lo más profundo de la cultura institucional y que explican lo visible o emergente.

\section{Cuadro 2. Resultados del análisis con la técnica del lceberg}

\begin{tabular}{|c|c|c|}
\hline $\begin{array}{l}\text { 1er nivel: } \\
\text { Lo visible }\end{array}$ & $\begin{array}{l}\text { 2do nivel: } \\
\text { Las Prioridades }\end{array}$ & $\begin{array}{l}\text { 3er nivel: } \\
\text { Elementos nucleadores }\end{array}$ \\
\hline $\begin{array}{l}\text { - Todos tienen el documento proyecto de } \\
\text { centro en su poder. } \\
\text { - En el cuestionario, la totalidad de las } \\
\text { maestras expresan que han participado en } \\
\text { la elaboración del proyecto de centro. } \\
\text { - Las maestras de primaria e inicial no se } \\
\text { ven (están contra turno). } \\
\text { - Los momentos de encuentro de la } \\
\text { directora con las maestras son en } \\
\text { febrero, en los recreos (con las que no le } \\
\text { corresponde cuidarlo), en las visitas de } \\
\text { clase. } \\
\text { - Directora desbordada, hiperdemandada, } \\
\text { sin tiempo para planificar la jornada. En } \\
\text { su escritorio suena permanentemente el } \\
\text { teléfono, es solicitada por padres, alumnos } \\
\text { y maestras. } \\
\text { - Cada vez hay más niños con dificultades } \\
\text { de aprendizaje. } \\
\text { - Falta participación y apoyo de las familias } \\
\text { en el proceso de formación de sus hijos. } \\
\text { - Algunos problemas de conducta. } \\
\text { - Faltan algunos espacios físicos para } \\
\text { primaria. }\end{array}$ & $\begin{array}{l}\text {-No hay espacio } \\
\text { de coordinación o } \\
\text { encuentros entre las } \\
\text { maestras y de éstas } \\
\text { con la dirección. } \\
\text {-No hay tiempo para } \\
\text { reunirse a planificar } \\
\text { acciones. } \\
\text {-Algunos problemas } \\
\text { de orden y } \\
\text { disciplina. } \\
\text {-Falta trabajar más } \\
\text { en valores. } \\
\text {-Falta más trabajo } \\
\text { con las familias. } \\
\text {-Grupos demasiado } \\
\text { numerosos. }\end{array}$ & $\begin{array}{l}\text { - Poca presencia de espacios } \\
\text { de participación y de reflexión } \\
\text { colectiva entre los docentes, lo } \\
\text { que limita las posibilidades de } \\
\text { hacer con otros, de compartir } \\
\text { derechos y responsabilidades, } \\
\text { así como realizar acuerdos, } \\
\text { alianzas y negociaciones en los } \\
\text { que cada uno sienta que aporta, } \\
\text { pero también que recibe. } \\
\text { - Todas las acciones que } \\
\text { impliquen realización de } \\
\text { acuerdos dependen de la buena } \\
\text { voluntad de las maestras y de la } \\
\text { directora. } \\
\text { - Poca cultura de participación, } \\
\text { lo que se manifiesta también } \\
\text { en la falta de trabajo con las } \\
\text { familias. } \\
\text { - Falta de involucramiento de } \\
\text { todos los actores en el proyecto } \\
\text { de centro. } \\
\text { - Poca unificación de criterios } \\
\text { básicos en la planificación. } \\
\text { - El tiempo de la dirección se ve } \\
\text { saturado por lo urgente. } \\
\text { - Se privilegian los espacios } \\
\text { individuales sobre los } \\
\text { colectivos. }\end{array}$ \\
\hline
\end{tabular}


A partir de la información obtenida se identificaron las Fortalezas y Debilidades de la organización, según la clasificación de dimensiones institucionales utilizadas por Frigerio y Poggi (1999).

Las Fortalezas son todos los factores o elementos internos y positivos con los que cuenta la escuela. Las Debilidades refieren a factores negativos, verdaderas barreras para lograr el buen funcionamiento de la organización.

Si bien en un análisis general es importante considerar las Oportunidades en tanto constituyen factores que una vez detectados pueden ser aprovechados, como las Amenazas que deben conocerse para diseñar estrategias para sortearlas; por la naturaleza de nuestro trabajo, teniendo en cuenta el tipo de organización y la situación que motivó la investigación, nos hemos centrado en las Fortalezas y Debilidades detectadas para cada dimensión institucional de la escuela, con el fin de identificar los recursos y procesos con los que se cuenta para poder avanzar hacia el plan de mejora.

Cuadro 3. Fortalezas y Debilidades de la Organización

\begin{tabular}{|c|c|c|}
\hline $\begin{array}{l}\text { Dimensión } \\
\text { institucional }\end{array}$ & Fortalezas & Debilidades \\
\hline Organizacional & $\begin{array}{l}\text { - La Directora muestra preocupación } \\
\text { y deseo de trabajar en la mejora de la } \\
\text { escuela. } \\
\text { - Existe un ideario que define la } \\
\text { identidad de la comunidad educativa. } \\
\text { - Existe PEC y han participado } \\
\text { diferentes actores en su elaboración } \\
\text { - Comunidad educativa manejable en } \\
\text { número. }\end{array}$ & $\begin{array}{l}\text { - PEC: existe el documento pero } \\
\text { falta involucramiento de toda la } \\
\text { comunidad educativa. } \\
\text { - No se evidencia cronograma ni } \\
\text { temporalización de actividades. } \\
\text { - Falta de tiempo destinado a la } \\
\text { planificación educativa. } \\
\text { - Falta de articulación de todas las } \\
\text { dimensiones. } \\
\text { - Cultura balcanizada. }\end{array}$ \\
\hline Administrativa & $\begin{array}{l}\text { - Infraestructura nueva: gimnasio, } \\
\text { salones, biblioteca y salón multiuso. } \\
\text { - Grupo estable de docentes. } \\
\text { - Inversión en formación permanente } \\
\text { de los docentes. } \\
\text { - Adquisición de libros y revistas } \\
\text { pedagógicas. }\end{array}$ & $\begin{array}{l}\text { - Falta de espacio de coordinación } \\
\text { remunerado dentro del turno. } \\
\text { - Falta de encuentros e } \\
\text { intercambio entre maestras del } \\
\text { turno matutino y vespertino. }\end{array}$ \\
\hline $\begin{array}{l}\text { Pedagógico } \\
\text { didáctica }\end{array}$ & $\begin{array}{l}\text { - Maestras motivadas para mejorar } \\
\text { sus prácticas pedagógicas y } \\
\text { compartir experiencias. } \\
\text { - Buena disposición para trabajar en } \\
\text { equipo. } \\
\text { - Deseo de profundizar trabajo en } \\
\text { valores y con las familias. }\end{array}$ & $\begin{array}{l}\text { - Pocas instancias de trabajo en } \\
\text { equipo. } \\
\text { - Falta de tiempo para coordinar y } \\
\text { planificar acciones educativas. } \\
\text { - No se visualiza estrategias de } \\
\text { socialización de las experiencias } \\
\text { de aula. } \\
\text { - Pocos encuentros a lo largo del } \\
\text { año lectivo para reflexionar sobre } \\
\text { las prácticas. } \\
\text { - No está demasiado claro el } \\
\text { objetivo del proyecto de centro } \\
\text { para la totalidad de los docentes. }\end{array}$ \\
\hline Comunitaria & $\begin{array}{l}\text { - Permanencia en el barrio desde } \\
\text { 1931, (Colegio con historia en el } \\
\text { lugar). }\end{array}$ & $\begin{array}{l}\text { - Falta incorporar a los padres } \\
\text { como co-educadores. } \\
\text { - Escaso trabajo en red con otros } \\
\text { colegios de la congregación en } \\
\text { Latinoamérica. }\end{array}$ \\
\hline
\end{tabular}


Hemos encontrado que la problemática detectada se relaciona con:

- Falta de formación en gestión en los cuadros directivos

- El estilo de liderazgo y la calidad de la gestión que es débil, ya que se constata el entusiasmo y la voluntad de la Directora por superar estos problemas pero no encuentra la manera de hacerl;, esto se traduce en expresiones como "es difícil tener conversaciones técnico-pedagógica", el trabajo con "los padres no sabemos cómo pero habría que estudiarlo" (EE1). Para que el cambio se produzca es necesario que alguien lo lidere, lo gestione, lo planifique, fundamente, y facilite su avance de forma compartida.

- El documento correspondiente al PEC posee una declaración de principios y valores que es idéntica a la del ideario ( no evidenciándose una contextualización en el aquí y ahora), un objetivo general amplio e inespecífico, y algunas consideraciones muy generales sobre aspectos referentes a la dimensión didáctico pedagógica, estando totalmente ausentes las dimensiones administrativa, organizacional y comunitaria lo que refleja que el mismo no está completo o el desconocimiento de las dimensiones que deben ser abarcadas en dicho documento. Aunque resulte paradójico en el PEC no aparecen referencias a la dimensión pastoral

- Se encontró que el objetivo principal del PEC no está claro para todos los integrantes de la comunidad, y en algunos casos sus ideas no coinciden en absoluto con lo que se lee en el documento. Por lo tanto, las dificultades también surgen por tratarse de un proyecto que viene armando "de afuera", por lo que nuestro trabajo consistió en articularlo con la realidad de la escuela y sus estudiantes.

- Un modelo de organización jerárquico, donde se pseudo- responde al mandato de la dirección, sin efectivizar acciones que conecten las propuestas organizacionales con las prácticas de aula.

- El tipo de cultura organizacional de la escuela que según las tipologías presentadas en la primera sección, transita entre individualista y balcanizada, estancada, descaminada y fue percibida como "una cuestión de familia" (EE3- EE1).

- Se constató la falta de un espacio de tiempo institucionalizado destinado a la planificación educativa. Gimeno Sacristán y Pérez Gómez (2008:287), destacan la importancia de "la coordinación como un espacio de diseño curricular", ya que permite explorar las conexiones entre los saberes, seleccionar nuevos recursos didácticos, leer y reflexionar para la actualización disciplinar, evitando la rutinización de las prácticas. Así se genera el espacio para que los docentes tengan la posibilidad de ser verdaderos constructores del currículum, aspecto que se tomó específicamente en la estructuración del PMO.

- No existe PCC

- No se evidencian actividades con relación a la socialización de experiencias exitosas o de aquellas que no dan los resultados esperados por las maestras, a los efectos de reflexionar sobre las prácticas y generar aprendizaje organizacional. No se observan actividades que promuevan el pasaje del conocimiento tácito o personal, al explícito o público, lo que estaría habilitando a la gestión del conocimiento organizacional (Gairín, 2008)

- Los modelos de enseñanza y aprendizaje que sustentan las prácticas no están muy claros y no se constata construcción colectiva en este sentido.

\section{3.a.d. Acuerdos con la organización}

Una vez finalizado el diagnóstico se entregó el informe de avance a los directivos de la escuela y luego se realizó una reunión con todos los integrantes de la comunidad educativa de Primaria, a los efectos de presentar el resultado del diagnóstico a partir del cual se elaboró el plan de mejora organizacional. Los aportes de los docentes también fueron considerados como insumos en la elaboración del mismo. Se realizaron los siguientes acuerdos para elaborar el plan de mejora: 
Acuerdos relacionados a aspectos instrumentales:

- El plan de mejora se realizaría en base al problema que surgió del diagnóstico (dificultades en la planificación institucional en Educación Primaria y su articulación con la planificación de aula)

- Se constituiría un equipo de trabajo para la elaboración del plan de mejora

- Las Fortalezas identificadas en la escuela serán utilizadas como puntos de apalancamiento (Senge, 1992) para afrontar las Debilidades vinculadas al problema.

Acuerdos asociados a aspectos vinculados a cambio en la cultura organizacional:

- La cultura organizacional y el estilo educativo deberán sustentarse en el ideario que describe una visión amplia del quehacer educativo orientado hacia la persona a formar pero deberán revisarse en un esfuerzo de contextualización

- El plan apuntará a unificar los objetivos de manera que la vida institucional tenga coherencia; la consolidación de una cultura colaborativa fomentando el diálogo didáctico entre los docentes

- El plan de mejora abarcará a las dimensiones organizacionales más fuertemente involucradas las cuales son de la más a la menos afectada: la Organizacional, la Administrativa y la Didáctico-pedagógica

\section{3.b. Con relación al PMO}

El grupo de trabajo asignado para participar del diseño del plan quedó constituido por la Directora de Primaria, una maestra, que por su larga experiencia de trabajo en la escuela fue invitada por la Directora a integrar el equipo, y la asesora/investigadora.

Los objetivos del PMO se definieron en el devenir de los encuentros de trabajo, y se determinaron en el marco de la misión de la organización como una contribución a los objetivos generales de la misma. Los objetivos, actividades, recursos, tiempos y metas del PMO se definieron vinculando la teoría que se encuentra en los documentos, con la práctica que se desarrolla en el aula. Planificamos la ejecución de acciones para garantizar la articulación entre el ideario, el PEC, el PCC y la PA. Los objetivos específicos fueron definidos siguiendo un criterio lógico de forma secuenciada y ordenada para poder alcanzar el objetivo general.

\section{3.b. a. Los objetivos}

Objetivo General del PMO:

Fortalecer y tender puentes entre el objetivo y misión del colegio expresados en el Ideario: el objetivo principal del Proyecto Educativo de Centro, el Proyecto Curricular de Centro (PCC - programa oficial contextualizado) y la planificación de aula realizada por los docentes, con el fin de mejorar los aprendizajes de los niños y de las niñas

Una vez definido y acordado el objetivo general se propuso como meta vinculada al mismo, la creación de una red interna sustentada desde un grupo de google, que permitiría la circulación permanente de materiales, información y de los trabajos que resultaran de los encuentros- taller a realizarse para llevar adelante el plan.

Este fin constituye un transversal a todo el proyecto y se sugirió que una vez culminado el mismo, la red siguiera siendo un "punto de encuentro" de la comunidad educativa. Los recursos con los que se contó fueron los equipos XO y la existencia de conectividad en la escuela. El responsable de la creación del grupo google y de asegurar la circulación de materiales y documentos, fue el docente de informática referente del Plan Ceibal. 
Objetivos específicos del PMO:

OE1: Promover el conocimiento de los diferentes modelos de enseñanza y aprendizaje que sustentan las prácticas docentes en la escuela, realizando acuerdos de base.

OE2: Analizar y articular los contenidos de los documentos del centro con las planificaciones anuales de centro y de aula.

OE3: Fomentar el intercambio y socialización de las prácticas de aula exitosas vinculadas al PEC, generando conocimiento organizacional.

3.b.b. El desarrollo curricular en la práctica: favoreciendo la articulación entre los niveles de planificación

Para la implementación y evaluación del PMO se previeron siete encuentros- taller con los integrantes de la comunidad educativa de Primaria. Se acordó que las responsables de la moderación de los mismos serían la Directora de Primaria y la maestra referente creando los andamiajes entre los conocimientos previos y los objetivos establecidos. Con relación a esto, las producciones realizadas por los docentes en cada encuentro- taller se recogen a través de las fichas de trabajo que hemos diseñado para tales efectos.

El siguiente cuadro presenta para cada objetivo específico, las actividades diseñadas, los recursos necesarios, los responsables y los logros proyectados (Metas).

\begin{tabular}{|c|c|c|c|c|}
\hline $\begin{array}{l}\text { Objetivos } \\
\text { específicos }\end{array}$ & Actividades & Recursos & Responsables & $\begin{array}{l}\text { Logros } \\
\text { proyectados } \\
\text { Metas }\end{array}$ \\
\hline $\begin{array}{l}\text { Objetivo } 1 \\
\text { Promover el } \\
\text { conocimiento de } \\
\text { los diferentes } \\
\text { modelos de } \\
\text { enseñanza y } \\
\text { aprendizaje que } \\
\text { sustentan las } \\
\text { prácticas docentes } \\
\text { en la escuela, } \\
\text { realizando } \\
\text { acuerdos de base. }\end{array}$ & $\begin{array}{l}\text { 1-a Identificación de } \\
\text { materiales sobre la } \\
\text { temática en la biblioteca } \\
\text { pedagógica en el centro } \\
\text { educativo } \\
\text { 1-b Encuentro-Taller I } \\
\text { Lectura reflexiva de } \\
\text { diferentes materiales } \\
\text { que aportan teoría y } \\
\text { estrategias de enseñanza } \\
\text { - aprendizaje para renovar } \\
\text { las prácticas. Ejercicio } \\
\text { (ficha de trabajo I) } \\
\text { 1-c Creación de una red } \\
\text { interna a la comunidad } \\
\text { educativa articulada a } \\
\text { través de un grupo google } \\
\text { 1-d Encuentro- Taller } \\
\text { IICharla con experto y } \\
\text { realización de acuerdos de } \\
\text { base entre los docentes } \\
\text { 1-e Elección consensuada } \\
\text { de alguna estrategia } \\
\text { didáctica y planificando en } \\
\text { función de ella actividades } \\
\text { áulicas. Ejercicio (ficha de } \\
\text { trabajo II) }\end{array}$ & $\begin{array}{l}\text {-Salón multiuso } \\
\text {-Libros } \\
\text {-Revistas } \\
\text { Pedagógicas } \\
\text {-Documentos: } \\
\text { Ideario, PEC, } \\
\text { Programa } 2008 \\
\text {-papel } \\
\text { - fotocopias } \\
\text {-palelógrafo } \\
\text {-insumos de } \\
\text { informática } \\
\text {-pantalla } \\
\text {-cañón } \\
\text {-marcadores } \\
\text {-pizarra } \\
\text {-cámara de fotos } \\
\text { (para documentar } \\
\text { los encuentros) } \\
\text { - Equipos XO de los } \\
\text { docentes } \\
\text { - Conectividad } \\
\text {-Invitado experto } \\
\text { Ficha de trabajo I y II }\end{array}$ & $\begin{array}{l}\text { 1-a Dirección y } \\
\text { maestra referente } \\
\text { 1-b Dirección, } \\
\text { maestra referente } \\
\text { 1-c Dirección, } \\
\text { maestra referente } \\
\text { y docente de } \\
\text { informática } \\
\text { referente de Plan } \\
\text { ceibal } \\
\text { 1-d Dirección, } \\
\text { maestra referente } \\
\text { e invitado experto } \\
\text { en la temática }\end{array}$ & $\begin{array}{l}\text { 1-a Un dossier } \\
\text { diseñado } \\
\text { 1-b } 80 \% \text { de los } \\
\text { docentes reconoce } \\
\text { el modelo de } \\
\text { enseñanza y } \\
\text { aprendizaje que } \\
\text { subyace en su } \\
\text { práctica } \\
\text { 1-c una dirección } \\
\text { del grupo google } \\
\text { creada y en uso } \\
\text { 1-d } 80 \% \text { asisten y } \\
\text { realizan acuerdos } \\
\text { de base con otros } \\
\text { docentes } \\
\text { 1-e } 80 \% \text { planifican } \\
\text { encuentros- taller } \\
\text { aula actividad de } \\
\text { dichos acuerdos } \\
\end{array}$ \\
\hline
\end{tabular}




\begin{tabular}{|c|c|c|c|c|}
\hline $\begin{array}{l}\text { Objetivo } 2 \\
\text { Analizar y articular } \\
\text { los contenidos de } \\
\text { los documentos } \\
\text { del centro con las } \\
\text { planificaciones } \\
\text { anuales de centro } \\
\text { y de aula. }\end{array}$ & $\begin{array}{l}\text { 2-a Encuentro- Taller } \\
\text { III Elección del o de las } \\
\text { Áreas de Conocimiento } \\
\text { (Matemático, de Lenguas, } \\
\text { de la Naturaleza, Social, } \\
\text { Corporal) que abordará el } \\
\text { PCC 2011 en función del } \\
\text { diagnóstico de situación } \\
\text { de partida de los niños. } \\
\text { Fundamentación. } \\
\text { Lectura de los contenidos } \\
\text { del diseño curricular de } \\
\text { base en relación al Área } \\
\text { seleccionada. } \\
\text { 2-b Encuentro- Taller } \\
\text { IV Definición de los } \\
\text { objetivos del PCC y } \\
\text { acuerdos en base a: } \\
\text { qué, cuándo y cómo hay } \\
\text { que enseñar (opciones } \\
\text { metodológicas) y qué } \\
\text { cuándo y cómo hay que } \\
\text { evaluar; contextualizando } \\
\text { la propuesta para } \\
\text { esta escuela y para la } \\
\text { generación } 2011 . \\
\text { 2-c Encuentro- Taller V } \\
\text { Realización en grupos } \\
\text { de a dos docentes de } \\
\text { una planificación en } \\
\text { cascada partiendo del } \\
\text { ideario y terminando en la } \\
\text { planificación de aula }\end{array}$ & $\begin{array}{l}\text {-Salón multiuso } \\
\text {-Documentos: } \\
\text { Ideario, PEC, } \\
\text { Programa 2008: } \\
\text { redes conceptuales } \\
\text { pág. 109, } \\
\text { Contenidos por Área } \\
\text { del conocimiento } \\
\text { pág. 138, } \\
\text { ejemplificaciones } \\
\text { pág. 372, } \\
\text {-evaluación } \\
\text { diagnóstica 2011 } \\
\text {-papel } \\
\text { - fotocopias } \\
\text {-palelógrafo } \\
\text {-insumos de } \\
\text { informática } \\
\text {-pantalla } \\
\text {-cañón } \\
\text {-marcadores } \\
\text {-pizarra } \\
\text {-cámara de fotos } \\
\text { (para documentar } \\
\text { los encuentros) }\end{array}$ & $\begin{array}{l}\text { 2-b Dirección y } \\
\text { maestra referente }\end{array}$ & $\begin{array}{l}\text { 2-b UN documento } \\
\text { referente al PCC } \\
\text { 2-c 80\% de los } \\
\text { docentes pone } \\
\text { en práctica la } \\
\text { articulación de } \\
\text { la planificación } \\
\text { institucional con la } \\
\text { de aula }\end{array}$ \\
\hline $\begin{array}{l}\text { Objetivo } 3 \\
\text { Fomentar el } \\
\text { intercambio y } \\
\text { socialización de } \\
\text { las prácticas de } \\
\text { aula exitosas, } \\
\text { vinculadas al } \\
\text { PEC, generando } \\
\text { conocimiento } \\
\text { organizacional. }\end{array}$ & $\begin{array}{l}\text { 3-a Encuentro -Taller VI } \\
\text { Definición y acuerdos con } \\
\text { relación a qué se entiende } \\
\text { por "buenas prácticas" o } \\
\text { "prácticas exitosas" para } \\
\text { esta escuela. } \\
\text { 3-b Encuentro -Taller VII } \\
\text { Proposición de actividades } \\
\text { que efectivamente se } \\
\text { vinculen al PEC, que sean } \\
\text { consideradas motivadoras } \\
\text { e innovadoras por los } \\
\text { docentes, y que hayan } \\
\text { dado buenos resultados } \\
\text { en los aprendizajes de los } \\
\text { alumnos. } \\
\text { 3-c Construcción de } \\
\text { un banco de prácticas } \\
\text { exitosas a disposición de } \\
\text { todos los docentes. }\end{array}$ & $\begin{array}{l}\text {-Salón multiuso } \\
\text { - fotocopias } \\
\text {-palelógrafo } \\
\text {-insumos de } \\
\text { informática } \\
\text {-pantalla } \\
\text {-cañón } \\
\text {-marcadores } \\
\text { - pizarra } \\
\text {-cámara de fotos } \\
\text { (para documentar } \\
\text { los encuentros) } \\
\text { - estadísticas de } \\
\text { los resultados } \\
\text { académicos } \\
\text { obtenidos por los } \\
\text { alumnos en el } 2010 \\
\text {-Insumos de } \\
\text { informática } \\
\text {-conexión a internet }\end{array}$ & $\begin{array}{l}\text { 3-a Dirección } \\
\text { y maestra } \\
\text { referente } \\
\text { 3-b Dirección } \\
\text { y maestra } \\
\text { referente }\end{array}$ & $\begin{array}{l}\text { 3-a Un documento } \\
\text { que caracteriza las } \\
\text { "buena prácticas" } \\
\text { 3-b } 80 \% \text { de los } \\
\text { docentes comparte } \\
\text { sus experiencias } \\
\text { con los demás } \\
\text { en encuentros } \\
\text { presenciales. } \\
\\
\text { 3-c } 75 \% \text { de las } \\
\text { maestras ofrece } \\
\text { su trabajo al banco } \\
\text { de prácticas que } \\
\text { circula por la red } \\
\text { 3-d } 20 \% \text { de } \\
\text { los resultados } \\
\text { obtenidos por los } \\
\text { alumnos mejoran } \\
\text { en comparación con } \\
\text { el año anterior }\end{array}$ \\
\hline
\end{tabular}


A continuación se presentan las fichas de trabajo elaboradas para el desarrollo de las actividades 1 -b y 1 -e
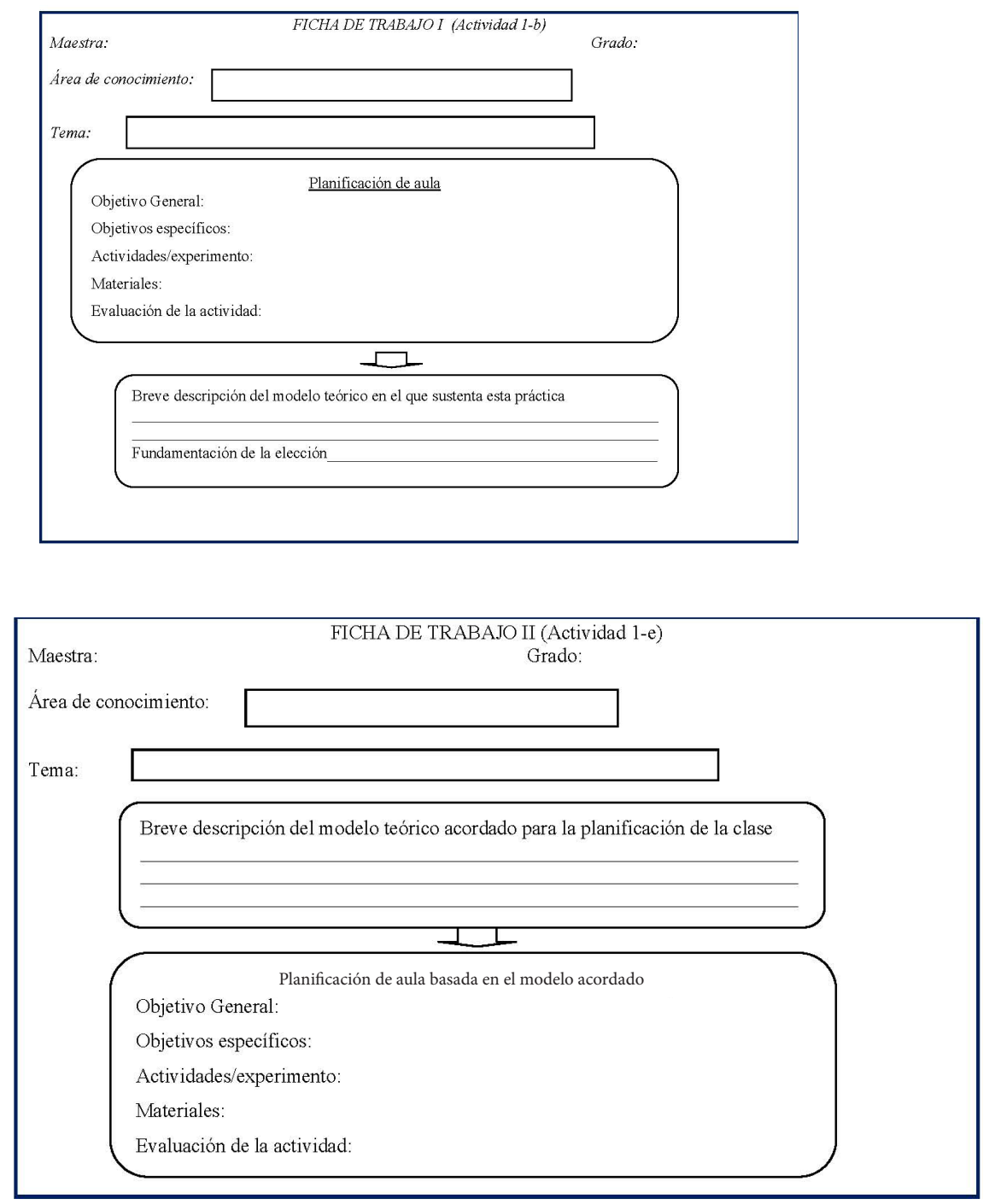

La planilla de sustentabilidad incluyo los siguientes dispositivos de monitoreo:

Dispositivo 1. Una planilla de monitoreo del Plan de Mejora, permite registrar el cumplimiento de los objetivos específicos planificados en el tiempo previsto.

Dispositivo2. Una encuesta de opinión para conocer el grado de satisfacción de los docentes con la experiencia.

Dispositivo3. Matriz de valoración o rúbrica que se elaboró para averiguar cómo está aprendiendo cada alumno en cada área del currículo, y darle un valor más objetivo y consistente a las calificaciones tradicionales expresadas en números o letras. Este tipo de dispositivo de evaluación caracteriza a la enseñanza para la comprensión.

Dispositivo4. Análisis documental comparativo para conocer el impacto del plan en los resultados de aprendizaje. Se analizan e interpretan colectivamente los datos obteniéndose información nueva que genera conocimiento sobre la escuela. 


\section{Conclusiones}

Finalizada la etapa del Diagnóstico, pudimos afirmar que nos encontramos ante una escuela con larga permanencia en el barrio, cuya Directora muestra preocupación y deseo de trabajar en la mejora y donde existe un ideario que define los rasgos de identidad; un Proyecto Educativo de Centro (PEC); una comunidad educativa manejable en número y un plantel estable de maestras motivadas para mejorar sus prácticas pedagógicas y compartir experiencias (fortalezas de la organización). Estas fortalezas identificadas en la escuela, fueron utilizadas como puntos de apalancamiento (Senge, 1992) para afrontar las debilidades vinculadas al problema.

El diagnóstico organizacional realizado en el marco del presente proyecto de investigación, permitió, entre otros aspectos, conocer el momento o estadio (Gairín, 2000) en el cual se encuentra la organización.

Basado en los datos recogidos y al análisis de los mismos, se observó que la escuela se encuentra en el segundo estadio u organización como contexto, ya que existe una posición activa por parte de la misma, que se ha explicitado a través del PEC donde se definen los objetivos que se esperan conseguir. Esto no significa que en la práctica se haya pasado de las acciones individuales de los docentes a acciones colaborativas asumidas por todos.

Con relación a este diagnóstico se implementó un plan de mejora que apuntó a que la escuela evolucione gradualmente hacia un estadio organizacional superior. Elegir las estrategias dinamizadoras más apropiadas, resulta clave en este proceso, ya que de la buena selección de las mismas, dependerá el grado de adhesión, compromiso y utilidad que encuentren los integrantes de la comunidad educativa en la propuesta para el cambio.

Se propusieron instancias para sensibilizar sobre el desarrollo organizacional, para fomentar la importancia de pasar del conocimiento tácito al explícito o colectivo, para promover el desplazamiento hacia un modelo de organización que aprende, que genera y gestiona el conocimiento.

Retomamos en Villa Sánchez (2008:261), la afirmación de que los PMO funcionan como mallas consistentes que sostienen y "revitalizan el PEC, el PCC y las programaciones didácticas haciéndolas aterrizar en la acción docente cotidiana”.

Si bien un plan de mejora constituye una intervención puntual que se implementa, desarrolla y evalúa en no más de un año, a modo de piedra que cae en un lago, genera círculos concéntricos que han de expandirse en la escuela toda, llegando a cada una de sus dimensiones.

Así, la elaboración del plan de mejora ha provocado modificaciones en el PEC, que fue repensado, reformulado y contextualizado; ha generado la necesidad de crear el PCC que ha movilizado la dimensión didáctico-pedagógica, ya que las maestras y el equipo de dirección manejan la idea de profundizar en la didáctica de la comprensión e incursionar en el programa PAI (Proyecto de activación de las Inteligencias).

Estos aspectos van abriendo un posible camino para el desarrollo de la organización desde una situación de "contexto de actuación", a una escuela que aprende y genera conocimiento sobre sí misma.

A la luz de lo que hemos comprobado en este trabajo, podemos sostener que comenzar a pensar en la autonomía de los centros educativos es fomentar el protagonismo gradual de los mismos, para poder dar respuestas locales a problemas locales.

Incluir en la agenda académica de las instituciones educativas la gestión por proyectos y la autonomía gradual de los centros, seguramente será un proceso complejo que no estará libre de tensiones, pero necesario, para articular los mandatos de la Administración con las propuestas que realiza el centro, en función de la particularidad de su demanda para el logro de mejores resultados en los aprendizajes. 
De esta manera se estaría cumpliendo con uno de los fines de toda organización educativa, que consiste en la transmisión de la herencia cultural realizada a través de la distribución de los saberes por medio del desarrollo curricular, formando así a las nuevas generaciones con el objeto de ofrecer herramientas que permitan su inclusión social y futura inserción en el mundo del trabajo.

\section{Bibiliografía}

Aguerrondo, I. y otros. 2002. "La escuela del futuro II. Cómo planifican las escuelas que innovan". Buenos Aires: Papers Editores.

ANEP/CEP. 2008. Programa de Educación Inicial y Primaria. Año 2008. Montevideo: ANEP. Antúnez, S., et. al. 1997. Del Proyecto Educativo a la Programación de Aula. Barcelona: Graó. Bernal Torres, C. 2006. Metodología de la Investigación para la Administración, economía, humanidades y ciencias sociales. México: Pearson Educación.

Blythe, T. 1999. La Enseñanza para la Comprensión. Buenos Aires: Paidós.

Bryk, A. \& Driscoll, M.E.1988. The School as a Communit. Theoretica Foundatios, Contextual Influences and Consequences for Students and Teachers. Working Paper 88/1105. Chicago: The University of Chicago.

Cardozo, S. 2008. Políticas educativas, logros y desafíos del sector en Uruguay 19902008. Cuadernos de la ENIA 2010- 2030. Serie: Políticas de educación.

Castillo, J.C. 2000. EI PES en síntesis. Maestría en Políticas Sociales. Panamá: icasePanamá.

De la Torre, S. 1998. Cómo innovar en los centros educativos. El estudio de casos. Madrid: Editorial Escuela Española.

Dibarboure, M. 2007. Pensando en la enseñanza y sus dificultades. Quehacer educativo Año XVII - No 86 Publicación de FUM-TEP.

Domingo, J. 2005. Asesoramiento al Centro Educativo. Barcelona: Octaedro- EUB.

Farneda, D. 2000. EI Proyecto Educativo Institucional en un Colegio en Pastoral. Montevideo: AUDEC.

Fernández, L. 2001. Instituciones Educativas. Buenos Aires: Paidós.

Frigerio, G. y Poggi, M. 1996. El análisis de la institución educativa. Hilos para tejer proyectos. Buenos Aires: Editorial Santillana S.A.

Frigerio, G. y Poggi, M. 1999. Las instituciones educativas. Cara y Ceca. Buenos Aires: Editorial Troquel S.A.

Fullan, M. y Hardgreaves, A. 1996. La escuela que queremos. Los objetivos por los que vale la pena luchar. Buenos Aires: Amorrortu/SEP Biblioteca para la Actualización del Maestro.

Gairín, J. 2000. Cambio de cultura y organizaciones que aprenden. Educar 27. Barcelona: Publicaciones de la Universidad Autónoma de Barcelona.

Gairín, J. 2004. Mejorar la sociedad, mejorando las organizaciones educativas. Bilbao: ICE de la U. Deusto- Ed. Mensajero, págs 77-128.

Gairín, J. 2008: Las comunidades formativas de aprendizaje en el contexto institucional. En: Las comunidades formativas de aprendizaje, Una experiencia en los institutos normales superiores de Bolivia. La Paz: Agencia Española de Cooperación Internacional (AECI).

Gimeno Sacristán, J y Pérez Gómez, A. (2008). Comprender y transformar la enseñanza”. Madrid: Morata. 
Guarro Pallas, A. 2005. Los procesos de cambio educativo en la sociedad compleja. Madrid: Pirámide.

Hargreaves, A. 1996. Profesorado, cultura y postmodernidad (Cambian los tiempos, cambia el profesorado). Madrid: Morata.

Hopkins, D. 1996. "Estrategias para el desarrollo de los centros educativos" en II Congreso Internacional sobre Dirección de centros Docentes. ICE de la Universidad de Deusto, 337-404. Latorre, A., et al. 2005. Bases Metodológicas de la Investigación Educativa. Barcelona: Ed. Experiencia.

Litwin, E. 2008. Las configuraciones didácticas. Buenos Aires: Paidos.

López Yañez, J., et.al. 2002. Análisis de organizaciones educativas a través de casos. Madrid: Síntesis Educación.

Lugo, T. y Sampedro, R. 2009. Seminario: Planificación Estratégica en la Gestión Educativa. Montevideo: Universidad ORT Uruguay. Material de clase sin publicar.

Matus, C. 1993. Estrategia y Plan. Madrid: Siglo Veitiuno Editores.

Morin, E. 1999. Los siete saberes necesarios para la educación del futuro. París: UNESCO. Morin, E., et al. 2003. Educar en la Era Planetaria. Barcelona: Editorial Gedisa S.A.

Nonaka, I. y Takeuchi, H. 1999. La organización creadora de conocimiento. Cómo las compañías japonesas crean la dinámica de la innovación. México: Oxford University Press.

Rodríguez, D. 2006. Modelos para la creación y gestión del conocimiento: una aproximación teórica. Educar 37 pág. 25-39 Barcelona: Universitat Autònoma de Barcelona Departament de Pedagogía Aplicada.

Rodríguez Gómez, G., et.al. 1999. Metodología de la investigación cualitativa. Málaga: Ediciones Aljibe.

Rué, J. 2000. Autoevaluación institucional: propósitos, agentes y metodología. Pedagogía Aplicada. UAB.

Sautu, R. 2003. Todo es teoría. Objetivos y métodos de investigación. Buenos Aires: Ediciones Lumiere.

Senge, P. 1992. La quinta disciplina. Barcelona: Ediciones Granica S.A.

Tedesco, J.C. 2005. ¿Cómo superar la desigualdad y la fragmentación del sistema educativo argentino? Buenos Aires: IIPE-UNESCO.

Tejera, A. 2003. Analizando la Institución y su Cultura. Montevideo. Universidad ORT.

Vázquez, MI. 2007. Gestión educativa en acción. La metodología de casos. Instituto de Educación: Universidad ORT Uruguay.

Vázquez, MI. 2008. La Planificación Institucional. Material de apoyo. Master en Gestión Educativa. Instituto de Educación: Universidad ORT Uruguay.

Villa Sánchez, A. 2008. Innovación y cambio en las organizaciones educativas. V congreso internacional sobre Dirección de Centro Educativos. Bilbao: I.C.E. Universidad de Deusto.

.Watzlawick, P. et al. 1985. Cambio. Barcelona: Herder.

\section{Documentos electrónicos}

ANEP/CODICEN /DIEE. 2010. Uruguay en PISA 2009. Primeros resultados en Ciencias, Matemática y Lectura del Programa Internacional de Evaluación de Estudiantes. Informe Ejecutivo. Programa PISA Uruguay. [online] [citado enero 2011]. [Fecha de consulta: enero 2011]. 
Disponible en internet en enero de 2011: http://www.anep.edu.uy/anepdata/0000019081.pdf

ANEP/Observatorio de la Educación. 2009. Definiciones. [online] [citado febrero 2011]. [Fecha de consulta: febrero 2011]. Disponible en internet en febrero de 2011: http://www.anep.edu.uy/ observatorio/paginas/definiciones.htm\#

Barriga, S. 1979. El Análisis Institucional y la Institución del Poder. Tercera Semana de Psicosociología. Universidad Autónoma de Barcelona. [online] [citado marzo 2011]. [Fecha de consulta: marzo 2011]. Disponible en internet en marzo de 2011:

http://www.raco.cat/index.php/QuadernsPsicologia/article/viewFile/200610/268124

-Cantón Mayo, I. 2004. Planes de Mejora de los centros educativos. Editorial: Aljibe, España. [online] [citado febrero 2011]. [Fecha de consulta: febrero 2011]. Disponible en internet en febrero de 2011:http://pdf.rincondelvago.com/planes-de-mejora-en-los-centros-educativos_isabelcantonmayo.html

Murillo, P. 2008 . "La autoevaluación institucional: Un camino importante para la mejora de los centros educativos". OGE. Organización y Gestión Educativa. Revista del Fórum Europeo de Administradores de la Educación. Vol. 1, 13-17. [online] [citado enero 2011]. [Fecha de consulta: enero 2011]. Disponible en internet en enero de 2011: http://prometeo.us.es/idea/ publicaciones/paulino/4a.pdf

Real Academia Española. 2001.22 ${ }^{a}$ Edición. [online] [citado enero 2011]. [Fecha de consulta: enero 2011]. Disponible en internet en enero de 2011: http://www.rae.es/rae.html http://buscon.rae.es/drael/SrvltConsulta?TIPO_BUS=3\&LEMA=prospectiva.

R.O.U. Ley General de Educación N ${ }^{0}$ 18.437. 2009. [online] [citado enero 2011]. [Fecha de consulta: enero 2011]. Disponible en internet en enero de 2011:

http://www.ces.edu.uy/ces/index.php?option=com_content\&view=article\&id=569\%3Aley-no18437-ley-general-de-educacion-160109\&catid=55\%3Anormativa\&ltemid=78

Tedesco, J.C. 2007. Los pilares de la educación del futuro. [online] [citado marzo 2011]. [Fecha de consulta: marzo 2011]. Disponible en internet en marzo de 2011:

http://www.oei.es/noticias/spip.php?article521

Tedesco, J.C. 2011. Los desafíos de la educación básica en el siglo XXI. Revista iberoamericana de educación. $N^{\circ}$ 55, pp. 31-47 (issn: 1022-6508) [online] [citado febrero 2011]. [Fecha de consulta: febrero 2011]. Consultado en noviembre de 2011 en: http://www.rieoei.org/rie55a01.pdf

${ }^{*}$ Fecha de recibido: 31/01/2012

Fecha de aceptado: 12/04/2012

\footnotetext{
** Master en Gestión Educativa y Diploma en Planificación y Gestión Educativa, Universidad ORT Uruguay. Profesora de Ciencias Biológicas, Instituto de Profesores Artigas. Profesora Referente de Educación de la Sexualidad en Formación Docente y en Enseñanza Secundaria y Referente Institucional del proceso de implementación del protocolo de situaciones de Violencia Doméstica en Adolescentes para la Enseñanza Media. Tutora, Instituto de Educación, Universidad ORT Uruguay.
} 